Discussion Papers of the

Max Planck Institute for

Research on Collective Goods

2021/4

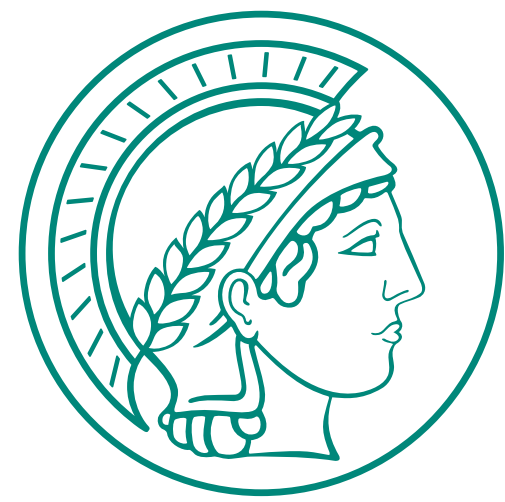

How Do People Trade Off Resources Between Quick and Slow Learners?

Ranveig Falch 


\title{
How Do People Trade Off Resources Between Quick and Slow Learners?
}

\author{
Ranveig Falch
}

February 2021 


\title{
How Do People Trade Off Resources Between Quick and Slow Learners?
}

\author{
Ranveig Falch \\ Norwegian School of Economics and Max Planck Institute for Research on Collective Goods
}

\begin{abstract}
How society invests in human capital is important for economic growth and social welfare. The paper reports from the first experiment designed to elicit people's preferences for how to prioritize educational resources, where 2,000 Americans trade off educational resources between quick and slow learners. I find that they give strong priority to slow learners and assign two thirds of the educational resources to this group. Both cost efficiency and the motivation of the learners causally affect the resource allocation. The findings provide important insights for the present policy debate on how to distribute educational resources in society.
\end{abstract}

JEL: C91, D01, D30, D63, I24, I28

Key words: Human capital investment, preferences, inequality, experiment, education [

E-mail: ranveig.falch@nhh.no I am grateful to Alexander W. Cappelen, Ingar Haaland, Henning Hermes, Philipp Lergetporer, Jan Potters, Charlotte Ringdal, Kjell Salvanes, Ingrid Sjursen, Eirik Andre Strømland, Sigrid Suetens, Erik $\emptyset$. Sørensen, Sigve Tjøtta, Bertil Tungodden, and numerous seminar participants for great comments and suggestions. The study is funded by the Norway-America Association (NORAM), the Research Council of Norway (FRIPRO-TOPPFORSK), the Centre for Ethics and Economics at the Norwegian School of Economics, and the Research Council of Norway through its Centres of Excellence Scheme, FAIR project No. 262675. This research project has been assessed and approved by the Norwegian Centre for Research Data (NSD). The study was pre-registered in the AEA RCT Registry; AEARCTR-0002615 and AEARCTR-0005231. 


\section{Introduction}

Investment in human capital is essential to promoting economic growth and social welfare in a society (Barro, 2001; Galor and Moav, 2004; Goldin and Katz, 2008; Schultz, 1961). 1 A critical question is how to distribute educational resources between students with varying learning abilities (Lafortune, Rothstein, and Schanzenbach, 2018, OECD, 2018) . 2 For decades, the key priority in most OECD countries has been to ensure that all students pass a minimum proficiency bar. More recently, there has been an increasing focus on strengthening the learning outcomes of all students, including high-ability learners (Every Student Succeeds Act 2015; OECD, 2018). Given the importance of these policies for society, puzzlingly little is known about people's preferences for how to prioritize educational resources (Busemeyer, Lergetporer, and Woessmann, 2018).

I conduct what is, to my knowledge, the first experiment designed to elicit people's preferences regarding how society should distribute educational resources. Inspired by policy debates (Finn and Wright, 2015; Goldstein, 2018), I focus on two distinct groups of students, quick and slow learners, and study how people trade off resources between these two groups. In an incentivized field experiment with a general population sample of over 2,000 Americans, I identify how people trade off actual educational resources between real students with differing learning abilities. I causally identify how the resource allocations depend on cost efficiency and on the motivation of the learners. Further, I shed light on the underlying mechanisms, including the role of beliefs about the relative returns to education and preferences regarding how to trade off equity and efficiency in human capital investment.

In the experiment, the participants act as impartial third parties to provide a direct expression of their moral preferences (Cappelen, Konow, Sørensen, and Tungodden, 2013). The participants distribute 12 hours of one-to-one tutoring between a quick and a slow learner, recruited via US-based non-governmental organizations (NGOs). While keeping important background characteristics constant between the learners, I provide additional treatment variations to study

\footnotetext{
${ }^{1}$ For further discussion of the link between human capital investment, economic growth and social welfare, see, e.g., Becker (1962); Black, Devereux, and Salvanes (2005); Goldin (2016); Manuelli and Seshadri (2014); Mincer (1958); Oreopoulos and Salvanes (2011).

${ }^{2}$ There are a number of other important questions in the literature on human capital investment, including how to respond to the boy crisis in education (Cappelen, Falch, and Tungodden, 2019b) and how to design fair and efficient adolescent skill policies (Heckman, 2006).
} 
mechanisms. Using a $2 \times 2$ design, I vary $i$ ) whether the participants receive information about the quick learner being highly motivated, and $i i$ ) whether there is an added cost of allocating tutoring to the slow learner. Further, I elicit beliefs about the relative improvement of the learners (given equal amounts of tutoring), and the relative societal and individual welfare losses associated with the quick and slow learners failing to reach their full learning potential.

The paper offers a number of findings on how people prefer to trade off educational resources between quick and slow learners. First, most of the participants give priority to the slow learner, with the quick learners being allocated one third of the educational resources on average. In the base treatment, even though most participants believe that the quick learners improve their school performance more with the tutoring, $70.4 \%$ of them allocate the majority of the educational resources to the slow learner. The priority given to the slow learners is robust across all treatments. The participants assign more tutoring to the slow learners even when it is not cost-efficient to do so, and when they know that the quick learner is highly motivated. Second, I show that cost efficiency causally matters for the distributive decision: the participants reduce the amount of tutoring to the slow learner when it becomes costlier. Third, I causally identify that the motivation of the students is also considered relevant for how educational resources should be distributed. Finally, I provide evidence suggesting that people's preferences for human capital investment policies are affected by individual welfare considerations, and in particular the welfare of the slow learner.

The results provide insights into several important policy debates. First, the findings shed light on the public support for the increased priority of highability learners in the US. This increased priority came with the signing of the Every Student Succeeds Act in 2015, which replaced the 2002 No Child Left Behind Act and its almost exclusive focus on improving the learning outcomes of struggling and low-performing students. The new act introduced tracking of high-ability learners and more funding opportunities to strengthen their learning outcomes, thereby mirroring the emerging shift in education policy priorities in the OECD (OECD, 2018). Relevant to these debated shifts in policy priorities, the present paper shows that, while people prioritize slow learners, they do not exclude efforts to strengthen the performance of quick learners to whom they allocate on average one third of the educational resources. Further, the present 
paper provides insight into the public support for education policies addressing the boy crisis, where boys are falling behind in school and dropping out at higher rates than girls (Autor and Wasserman, 2013, Cappelen et al. 2019b; OECD, 2017). Additionally, the paper sheds light on the public opinion on the equity-efficiency trade-off linked to how much should be invested in adolescent skill policies aimed at reducing inequality based on socioeconomic backgrounds (Elango, García, Heckman, and Hojman, 2015; Heckman, 2006; Marks, 2014). In both cases, additional resources are needed to help struggling and often unmotivated students reach a basic level of skills and avoid drop-out. Relevant to these debates, I find that people allocate the majority of the educational resources to the slow learners, despite believing that they are not very motivated and despite it not being cost-efficient.

The present study contributes to three strands of literature. The first studies how beliefs about pecuniary and nonpecuniary returns to human capital investment impact individual and parental human capital investment decisions (Almås, Cappelen, Salvanes, Sørensen, and Tungodden, 2016; Attanasio, Boneva, and Rauh, Forthcoming; Berry, Dizon-Ross, and Jagnani, 2020; Boneva and Rauh, 2017, 2018; Dizon-Ross, 2019; Jensen, 2010; Oreopoulos and Salvanes, 2011). The research has focused on understanding decisions on whether and how much to invest. I extend this literature by looking at a different type of human capital investment decisions, namely in whom people prefer to invest. $]^{3}$ In contrast to a parental perspective, the present paper examines people's preferences for human capital investments from a societal perspective. Taken together, the present paper extends the literature on preferences for human capital investment to the education policy domain, shedding light on people's preferences on important issues in current policy debates (Autor and Wasserman, 2013; Autor. 2014; Heckman, 2013; OECD, 2018).

The paper also contributes to the literature on people's attitudes towards education policy. The literature has largely focused on the support for public education spending as a whole, or relative to other government spending areas (Bursztyn, 2016; Busemeyer et al., 2018). There are also survey experiments on the effect of information provision on public support for various education poli-

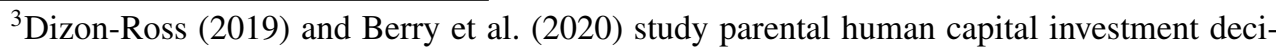
sions among poor families in Malawi. They find that the parents' investment level and distribution of resources between their children depend on their beliefs about their children's relative educational performance and abilities. 
cies: Lergetporer, Schwerdt, Werner, West, and Woessmann (2018) find that information about existing spending levels reduces support for increased spending levels and teacher salaries, while Lergetporer, Werner, and Woessmann (2020) study the effect of information about educational inequality on concerns for educational inequality, and the support for equity-oriented education policies to alleviate the inequality. Lergetporer et al. (2020) find that concern for educational inequality, and to some degree the support for equity-oriented policies, increases with information. I extend this literature by conducting an incentivized experiment on people's preferences for how to distribute educational resources in society. In contrast to the previous studies, I study how people make tradeoffs when dividing educational resources, and how people prefer to distribute limited funds between different types of learners.

Finally, the paper contributes to the literature on social preferences (Bolton and Ockenfels, 2000; Cappelen, Drange Hole, Sørensen, and Tungodden, 2007; Cappelen, Falch, and Tungodden, 2020; Charness and Rabin, 2002; Fehr and Schmidt, 1999; Konow, 2000, 2003) . 4 This literature has focused almost exclusively on preferences over distribution of income. I extend the literature to the education policy domain by having people distribute educational resources between learners. In line with the previous literature, the present study shows that efficiency concerns are often assigned less weight than concerns for inequality (Almås, Cappelen, and Tungodden, 2020). Finally, I inform the important issue of how to handle inequalities that arise from individual differences in natural ability. In contrast to previous findings, where inequalities due to differences in natural ability are considered fair (Cappelen, Sørensen, and Tungodden, 2010), I find that, in the education domain, people prefer to reduce inequalities that arise as a result of differences in natural learning ability.

The paper is organized as follows: Section 2 describes the participants and the experimental design, Section 3 outlines the main empirical strategy, Section 4 reports the results, and Section 5 concludes.

\footnotetext{
${ }^{4}$ Other articles studying social preferences and impartial behavior are, e.g., Andreoni, Aydin, Barton, Bernheim, and Naecker (2020); Bortolotti, Soraperra, Sutter, and Zoller (2017); Cappelen, Falch, Huang, and Tungodden (2019a); Cappelen et al. (2019b); Rodriguez-Lara and Moreno-Garrido (2012).
} 


\section{Participants and Experimental Design}

To collect experimental data on a general population sample, I combine the expertise and resources of an international data-collection agency and two NGOs that offer one-to-one tutoring programs. In the following, I explain the recruitment of participants and the implementation of the distributive decisions, before I outline the design.

\subsection{Participants and Implementation}

The participants were recruited in December 2017 using the data-collection agency Research Now $5^{5}$ I recruited 2,001 US participants (18+ years old) who are nationally representative on observable characteristics (gender, age, and geography). The participants were randomly allocated to four different treatments. Table 1 provides an overview of the background characteristics of the participants and a comparison with US census data. The share of males in the sample is 0.491 and the median age is 45 years. The sample is heterogenous in terms of education and income, with $33 \%$ of the sample having only completed highschool education or less, and with a median gross yearly household income of $\$ 45,000$. The share of persons reporting that they would vote Republican if there was an election tomorrow is 0.376 (the alternatives to Republican were Democratic or other). The share of people who have children is 0.640 . The ethnic diversity in participants' neighborhoods, as measured by the share of non-whites in the median neighborhood, is 0.282 . The median school quality in their districts, as measured by the average mean third-grade mathematics test scores in 2013, is 3.197 ${ }^{6}$ Compared to the data from the US Census Bureau, we observe that the sample is representative when it comes to gender, age, and geography. The median income is a bit lower and the educational attainment is slightly higher in the sample than in the US, while the median neighborhood characteristics for ethnic diversity and school quality mirror the medians in the

\footnotetext{
${ }^{5}$ They were sampled from the Research Now online panel, managed to be representative of the US population with respect to basic demographics. No data delivered by Research Now was excluded from the analysis in this paper.

${ }^{6}$ The neighborhood characteristics are based on coupling the participant ZIP-codes with information from the Opportunity Atlas, which are pre-specified for exploratory analysis. Details on the coupling are provided in Section A.3.2.
} 
US as a whole. 7

[Table 1 about here]

\subsection{Experimental Design, Base Treatment}

The participants distributed actual educational resources between anonymous students with different learning abilities. They divided 12 hours of one-to-one tutoring between a student classified as a quick learner and a student classified as a slow learner. To control beliefs about characteristics correlated with learning abilities, the participants were informed that the pair of students were both middle-school students from the US, from economically disadvantaged families, and that they were either two boys or two girls. 8 Finally, the participants were informed that some decisions regarding the allocation of tutoring would be randomly selected for implementation (five per cent). They did not receive information about how the decisions would be implemented. The experimental design allows me to identify how a general population sample of Americans distributes actual educational resources between real students, depending on whether the students are quick or slow learners.

The selected decisions were implemented in collaboration with two USbased NGOs. Both organizations focus on students from economically disadvantaged families in the US, earmarking the experimental incentives to provide one-to-one tutoring for middle-school students with this background, and according to gender as needed. The first organization, SMART, implemented the tutoring allocated to quick learners. SMART has a tutoring program for highly motivated middle-school students with strong academic potential (identified by their teachers) (https: / / www.thesmartprogram.org/). The second organization, Learn To Be, implemented the tutoring allocated to the slow learners. Learn To Be identified the learners who take more time and learn

\footnotetext{
${ }^{7}$ The main results presented in this paper are robust to probability weighting based on income and education.

${ }^{8}$ To elicit information on beliefs about the quick and slow learners' educational outcomes, I conducted an exploratory follow-up study with one thousand US adults recruited in an identical manner. They were presented with the same information about the two students as in the base treatment and asked about the two students' expected grade point averages (GPAs) as they leave middle school. The participants on average believed that the quick learner would do better than the US average (GPA of 3.31), and that the slow learner would do worse than the US average (GPA of 2.26). Detailed instructions are provided in Appendix A.4
} 
more slowly among their applicants, based on parent descriptions (https: //learntobe.org/). To minimize the influence on distributive behavior from beliefs about the two organisations, the participants did not receive information on how the tutoring would be implemented.

\subsection{Treatment Variations}

To identify causally whether beliefs about cost efficiency and beliefs about the motivation of the learners impact the distributive decision, I implemented a $2 \times 2$ experimental design, in which I varied the following factors:

- Whether the participant was informed that the quick learner is highly motivated.

- Whether there was an added cost (efficiency loss) associated with distributing tutoring to the slow learner.

This $2 \times 2$ design allows me to study how people trade off educational resources between quick and slow learners, and whether information about relative motivation and cost efficiency matters when making this trade-off. An alternative strategy for the motivation treatment would have been also to manipulate the information about the slow learner, but this was not feasible given the limits of the NGOs implementing the tutoring. The additional cost associated with distributing tutoring to the slow learner was implemented by decreasing the amount allocated to the quick learner by two hours for every hour allocated to the slow learner. In a between-individual design, the participants were randomly allocated to one of the treatments.

[Table 2 about here]

I provide the instructions given to the participants in T1 (Base) in Appendix A.3.3 and list the treatment variations subsequently. The word 'girls' is replaced with 'boys' for half of the sample. As pre-specified, I collapse the data within each of the four main treatments and disregard whether the distributive decisions were made for two boys or two girls, because I do not find evidence of a difference in distributive behavior based on the gender of the learners. ${ }^{9}$

\footnotetext{
${ }^{9}$ Table A.1 presents a balance test, which shows that the four treatments are not significantly different from each other with respect to the pre-specified background characteristics gender, political preference, age, having children, and having low socioeconomic status.
} 


\subsection{Survey on Beliefs and Attitudes}

To study underlying mechanisms, the participants were asked questions about their beliefs and attitudes after they had made their allocation decisions. Three questions concerned the allocation decision they had just made: (1) The main reason for their choice, (2) their beliefs about the relative motivations of the two students, and (3) their beliefs about the relative improvement of the students, given the same amount of tutoring. The next two questions were asked about two hypothetical individuals, a quick and a slow learner who have finished their education, but are equally distant from their full learning potential: (4) Which learner has a greater welfare loss in life and (5) which learner is associated with a greater welfare loss to society? In the final question, (6), the participants were asked to what extent they agreed with the following statement: "The US government should have a particular focus on helping low-performing children in school".

Question (1) is explorative and is used to elicit the main reason for each respondent's resource allocation, while question (2) is included to test whether the motivation treatments changed beliefs about the relative motivation of the learners. Questions (3), (4), and (5) relate to efficiency arguments and concern narrow and broad views on returns to education for society and for the two individuals. Question (6) is elicited to test the external validity of the experimental design. The full set of instructions for the beliefs and attitude questions are provided in Appendix A.3.4

\section{Empirical Strategy}

The following section outlines the main empirical strategy. I specified the empirical strategy in a pre-analysis plan, registered at the AEA RCT Registry before the data collection.

\subsection{Main Analysis}

In the main analysis, I identify treatment estimates relative to the base treatment, with and without control variables. The main outcome variable is the share of tutoring assigned to the quick learner, and I use the following empirical specifi- 
cation:

$$
\begin{array}{r}
u_{i}=\alpha_{0}+\alpha_{1} \text { Efficiency }_{i}+\alpha_{2} \text { Motivation }_{i}+ \\
\alpha_{3} \text { Efficiency }_{i} * \text { Motivation }_{i}+\boldsymbol{\alpha}_{4} \mathbf{X}_{i}+\varepsilon_{i}
\end{array}
$$

where $u_{i}$ is the share allocated by participant $i$ to the quick learner, and Ef ficiency and Motivation $_{i}$ are indicators referring to participant $i$ being in one of the efficiency treatments (T2 or T4) or one of the motivation treatments (T3 or T4), respectively. Efficiency $y_{i} *$ Motivation $_{i}$ is the interaction between the two. $\mathbf{X}_{i}$ is a vector of control variables, and $\varepsilon_{i}$ is an idiosyncratic error term. I report the regression with and without control variables. For all specifications, I use robust standard errors. I estimate (1) for the full sample of participants. As an alternative outcome variable, I use an indicator variable for assigning at least half of the tutoring to the quick learner.

Using this approach, I can identify the causal effect of $i$ ) introducing an added cost associated with distributing tutoring to the slow learner $\left.\left(\alpha_{1}\right), i i\right)$ the participant learning that the quick learner is highly motivated $\left(\alpha_{2}\right)$, and $\left.i i i\right)$ the interaction of the two $\left(\alpha_{3}\right)$.

\subsection{Heterogeneity, Background Characteristics}

I study whether there are particularly strong treatment effects on the allocation decision in some subgroups. I focus on the following background characteristics: gender, political orientation, age, whether the participant has children, and socioeconomic status based on income and education level. Regression (2) exemplifies the heterogeneity analyses by comparing the treatment effect of varying cost efficiency (T1 Base vs. T2 Efficiency) for male and female participants.

$u_{i}=\gamma_{0}+\gamma_{1}$ Efficiency $y_{i}+\gamma_{2}$ Femal $_{i}+\gamma_{3}$ Female $_{i} \times$ Efficiency fi $_{i}+\boldsymbol{\gamma}_{4} \mathbf{X}_{i}+\varepsilon_{i}$,

where $u_{i}$ is the share allocated by participant $i$ to the quick learner, Ef ficiency is an indicator for participant $i$ being in the efficiency treatment, Female $e_{i}$ is an indicator for participant $i$ being female, Female $_{i} \times E f$ ficiency $_{i}$ is an interaction term for participant $i$ being female and belonging to the efficiency treatment, $\mathbf{X}_{i}$ is a vector of control variables, and $\varepsilon_{i}$ is an idiosyncratic error term. I 
estimate (2) for the sample of participants in T1 (Base) and T2 (Efficiency). I use corresponding regression equations for the other dimensions of heterogeneity.

I replace $E f$ ficiency $_{i}$ and Female $_{i} \times$ Efficiency $_{i}$ with Motivation $_{i}$ and Female $_{i} \times$ Motivation $_{i}$ in (2) for the heterogeneity analysis of the treatment effect of T3 (Motivation) compared to T1 (Base), using instead the sample of participants in T1 (Base) and T3 (Motivation).

\section{Results}

First, I provide an overview of how the participants distribute educational resources between quick and slow learners. Then, I turn to the treatment analysis and causally identify the effects of varying cost efficiency and the motivation of the learners on the distribution of educational resources. Next, I provide a heterogeneity analysis based on the background characteristics, before finally analyzing the participants' beliefs to shed further light on underlying mechanisms.

\subsection{The Distributive Decisions}

Figure 1 provides an overview of the distributive decisions in the base treatment, using the share of tutoring assigned to the quick learner. We observe that the majority, $70.4 \%$, give priority to the slow learner by assigning more than half of the tutoring to the slow learner. The rest of the sample is split between those distributing the tutoring equally between the two learners (17.6\% of the sample) and those assigning most of it to the quick learner (12\% of the sample). The median participant assigns $33.3 \%$ of the tutoring to the quick learner, and the average share assigned to the quick learner is $36.8 \% .10$

[Figure 1 about here]

Result 1: The majority of participants, $70.4 \%$, prioritize the slow learner when distributing tutoring between a quick and a slow learner. The median participant assigns $33.3 \%$ to the quick learner.

\footnotetext{
${ }^{10}$ Figure A.1 provides an overview of the distributive decisions for the full sample, and Figure A.2 provides an overview of the distributive decisions by treatment.
} 


\subsection{Main Analyses}

Now, I turn to the regression analysis of the treatment manipulations. Table 3 reports treatment estimates relative to the base treatment, with and without control variables. The outcome variable in columns 1-3 is the share of tutoring assigned to the quick learner. The outcome variable in columns 4-6 is an indicator variable for assigning at least half of the tutoring to the quick learner.

[Table 3 about here]

In treatments $\mathrm{T} 2$ and $\mathrm{T} 4$, I manipulate the cost efficiency of allocating tutoring to the slow learner, making allocations to the slow learner more costly. We observe that when there is an added cost associated with allocating tutoring to the slow learner, the average share assigned to the quick learner is increased by $15.8 \%(0.058, p<0.001$, Table 3 , column 1$)$. The result remains practically unchanged when I include background variables for gender, political orientation, income, age, education, whether the participants have children (Table 3, column 2), and neighborhood characteristics (Table 3 , column 3), and is robust to multiple hypothesis adjustment ( $p=0.001$, Table A.6). The qualitative effect also remains robust to using an indicator for assigning at least half of the tutoring to the quick learner as the outcome variable. The participants are 12.8 percentage points more likely to assign at least half of the tutoring to the quick learner in the efficiency treatments compared with the base treatment $(p<0.001){ }_{11}^{11}$

In treatments T3 and T4, I manipulate beliefs concerning the relative motivations of the two learners. In Table 3 , we observe that, when the participants know that the quick learner is a highly motivated student, they assign a larger share of the tutoring to the quick learner compared to participants in the base treatment $(0.026, p=0.066$, or $7.1 \%$, column 1$)$. The result remains robust to the inclusion of the pre-specified background variables (Table 3, column 2) and to using an indicator for assigning at least half of the tutoring to the quick learner as the outcome variable $(0.055, p=0.062$, column 4). However, the effect is relatively small and not robust to multiple hypothesis adjustment ( $p=$

\footnotetext{
${ }^{11}$ To study whether the change in behavior is a result of shifted beliefs concerning the students' relative improvement from the tutoring, I compare beliefs about the relative improvement in the treatments with and without an added cost. I find no evidence of such a shift in beliefs $(p=0.620)$.
} 
0.115, Table A.6, nor to the exploratory analysis including neighborhood characteristics ( $p=0.104$, Table 3, column 3).

To shed light on underlying mechanisms, I study how beliefs concerning the relative motivations of the two learners are shifted by informing participants that the quick learner is a highly motivated student. I find that the beliefs are shifted by 0.186 standard deviations in the direction of believing the quick learner is (even) more motivated than the slow learner ( $p<0.000$, Table A.2, column 1). Furthermore, I identify the effect of the motivation treatments on participants' beliefs about the two learners' relative potential to improve their school performance given the same amount of tutoring. I do not find a significant effect ( $p=0.421$, Table A.2, column 3). Just as in the base treatment, only about one fifth of the participants in the motivation treatments believe that the slow learners would improve their school performance more than the quick learners. The majority instead believes that the quick learners would improve the most.

Result 2: The participants assign a larger share of tutoring to the quick learner as it becomes less cost-efficient to assign tutoring to the slow learner. There is also suggestive evidence that they increase the share to the quick learner when they learn that the quick learner is a highly motivated student.

In the combined treatment, I introduce both the added cost associated with allocating tutoring to the slow learner, as in $\mathrm{T} 2$, and information on the quick learner being highly motivated, as in T3. I do not find an interaction effect from combining the motivation and cost efficiency manipulations $(-0.031, p=$ 0.152 , column 1, Table 3). The result is robust to controlling for background characteristics, and to using the indicator for whether at least half of the tutoring is allocated to the quick learner as the outcome variable $(0.002, p=0.963$, column 3).

Result 3: The priority given to the slow learner is robust across all treatments, even when it is not a cost-efficient way to allocate resources, and despite participants' beliefs that the quick learners are more motivated and more likely to improve their school performance as a result of the tutoring.

From Table 3, we observe the correlation between observed background characteristics and distributive behavior. In line with the literature on inequality acceptance in the income domain (Almås et al., 2020, Cappelen et al., 2019b), 
we observe that females allocate a lower share to quick learners than do males $(-0.051, p<0.001$, column 2$)$. We further observe that younger people and people with low education distribute a larger share to the quick learners compared to their counterparts $(0.107, p<0.001,0.033$, and $p=0.008$, column 2$)$. The results on age and education are in line with findings from a survey of a general population sample in Germany, which asks to what degree the participants find educational inequality to be a problem (Lergetporer et al., 2020). In terms of political preferences, we observe a political consensus for the priority of the slow learner $(0.016, p=0.150$, column 2$)$. This is noticeable, given that Republicans are often found to accept more inequality than Democrats (Almås et al. 2020; Cappelen et al. 2019b). The result suggests that there is more political consensus for reducing inequalities in education, compared to inequalities in the income domain.

The average allocation decision does not vary significantly across income groups (above and below the median in the sample, $-0.019, p=0.155$, column 2 ), between people having children and not $(-0.019, p=0.120$, column 2$)$, nor in the explorative analysis between people from neighborhoods with learning outcomes above and below median $(0.003, p=0.795$, column 3$)$. However, I do find that people from more diverse neighborhoods assign a larger share to the quick learner, compared with people from less diverse neighborhoods $(0.046 p<0.001$, columns 3$)$. The correlation results are largely robust to the outcome variable being the indicator for giving less to the quick learner, with one exception; the difference between people with and without children is significant using this indicator variable $(-0.045, p=0.052$, column 5$)$.

\subsection{Heterogeneity Analyses}

In Table 4, I report the heterogeneity analyses, as specified in (2), focusing on the share allocated to the quick learner. As pre-specified, I compare how the allocation decisions in T1 (Base) and T2 (Efficiency), and T1 (Base) and T3 (Motivation) depend on gender, political preference, age, having children, and socioeconomic status.

[Table 4 about here]

I find that the effect of the efficiency treatment is strikingly robust across all subgroups. Within each subgroup, participants in the efficiency treatment 
assign a higher share to the quick learner, compared with participants in the base treatment (columns 1-5, Panel A). Moreover, I do not find any robust interaction effects $\sqrt[12]{2}$ Noticeably, all subgroups assign a larger share of tutoring to the slow learner even when there is an added cost associated with doing so (Panel A, Table 4). This is also true in the heterogeneity analysis, including the proxies for the quality of education and diversity in the participants' neighborhoods (Panel A, Table A.3).

For the motivation treatment, I do not find significant interaction effects. All estimates are positive, meaning that information on the quick learner being highly motivated leads the participants to assign less to the quick learner. However, the effects are relatively small and only significant for participants with children, where the treatment effect is 0.029 ( $p=0.081$, Panel B, Table 4), and for participants from neighborhoods which are less diverse than the median neighborhood $\left(0.038, p=0.035\right.$, Panel B, Table A.3) ${ }^{13}$

Result 4: In all subgroups, we observe a positive and highly significant effect of the efficiency treatment on the share of tutoring allocated to the quick learner. For the motivation treatment, the estimates are positive in all subgroups, but largely not significant. There are no strong interaction effects. Despite the treatment effects, slow learners are on average prioritized in all subgroups.

\subsection{Welfare Considerations}

An important question is whether welfare considerations are important for the distribution of educational resources, or whether the participants solely focus on human capital effects. To provide more information on this issue, I elicited beliefs about two welfare considerations that may influence the participants' distributive choices: $i$ ) maximizing welfare in society; and $i i$ ) maximizing the welfare of the two individuals involved. The societal welfare loss clearly includes the individual welfare losses, but also captures effects on the rest of society.

\footnotetext{
${ }^{12}$ The results in Table 4 suggest that the effect of the efficiency treatment is particularly strong among participants with low socioeconomic status compared to participants with higher socioeconomic status $(0.068, p=0.085$, column 5 , Panel A), but the difference is not robust to multiple hypothesis adjustments $(p=0.359$, Table A.8).

${ }^{13}$ The heterogeneity analysis for T1 (Base) vs. T4 (Efficiency and Motivation) is reported in Table A.4 The treatment effect is relatively robust across all subgroups, and there are no statistically significant interaction effects.
} 
While quick and slow learners who do not reach their full learning potentials may suffer individual welfare losses, society as a whole may suffer additional welfare losses from payments for unemployment benefits, lost tax revenues, less innovation, and so on.

To elicit beliefs about the two welfare considerations, I asked the participants about their beliefs regarding two hypothetical individuals, a quick and a slow learner, both of whom have finished their education, but who are equally distant from their full learning potential. The participants were asked $i$ ) which learner would be associated with a greater welfare loss to society and ii) which learner would experience a greater welfare loss in life.

[Figure 2 about here]

Figure 2 provides an overview of the self-reported beliefs for the full sample. ${ }^{14}$ Panel a) shows that half of the participants believe that the societal welfare loss would be the same independently of whether it were quick or slow learners not reaching their full learning potential. The rest of the participants are relatively evenly spread between those believing that there is a greater societal welfare loss associated with the quick learners not reaching their learning potentials $(25.8 \%)$ and those who consider that the greatest loss is associated with slow learners failing to reach their learning potential (25.4\%). Panel b) shows that relatively few participants $(21.2 \%)$ believe that quick learners who fail to reach their full learning potentials will suffer a greater welfare loss compared with slow learners not doing so. Almost half of the sample believe that the individual welfare losses will be the same for the two, while $33.4 \%$ believe that the slow learners will experience a greater welfare loss. In essence, the participants hold similar beliefs about the welfare losses to society and the welfare losses to the two individuals, except more participants believe that the slow learners will suffer greater individual welfare losses than quick learners from not reaching their full learning potentials, compared to their beliefs over the relative societal welfare losses. The increase is $5.6 \%$ relative to societal welfare, or 0.168 ( $p<$ 0.001 , paired t-test) on the 5-point scale on which both questions were asked.

As pre-specified, I analyze whether these beliefs are associated with the participants' distributive behavior using the sample in the base treatment. I identify

\footnotetext{
${ }^{14}$ The results are balanced across treatments. In joint F-tests with the reference category being the base treatment (T1), the elicited beliefs are not significantly different from each other across the four main treatments ( $\operatorname{Prob}>\mathrm{F}=0.3073$ and $\operatorname{Prob}>\mathrm{F}=0.2573$, respectively).
} 
whether there is a difference in allocation decisions between participants who believe that quick learners will suffer more, or as much as slow learners when they do not reach their full learning potentials, compared to participants who do not believe this. Table 5 provides results showing that the distributive behavior is significantly associated with beliefs about individual welfare losses, and that participants assign more educational resources to the individuals whom they believe will suffer more from not reaching their full learning potentials $(0.066, p=$ 0.001 , column 1). At the same time, there is on average no association between the allocations and beliefs about the relative welfare losses to society $(0.027$, $p=0.211$, column 3) 15

Result 5: The participants allocate more to the learner whom they believe will suffer more from not reaching his/her full learning potential, which suggests that allocations are affected by individual welfare considerations. There is no strong correlation between allocations and beliefs about the relative societal welfare losses.

The results suggest that people's preferences regarding the distribution of educational resources between students with different learning abilities are not only affected by cost efficiency, but also by a concern for the individual welfare of the students involved. In particular, participants who believe that slow learners will suffer greater welfare losses than quick learners from not reaching their full learning potential assign more educational resources to the slow learners.

[Figure 3 about here]

This interpretation is mirrored in the reasoning the respondents themselves give for their resource allocation. Directly after their distributive decision, each respondent answered the open question, "What was the main reason for your choice? Please explain." A total of 1622 participants provided a single main reason for the resource allocation, which fits one of four pre-determined categories. Figure 3 provides the categorized results ${ }^{16}$ Fully $70 \%$ report that the main reason for their allocation decision was to reduce inequality in outcomes between the students. An example is the participant who stated that "The slow learner takes more time to learn; therefore, he should receive more time to be

\footnotetext{
${ }^{15}$ Table 5 also provides the results using the full sample.

${ }^{16}$ Appendix A.5.2 provides details on the categorization.
} 
taught." This group of participants assigned on average $72.9 \%$ of the educational resources to the slow learner. Reducing inequality in inputs was the main reason for $22 \%$ who, in line with their reasoning, assigned on average $1 / 2$ of the tutoring to each learner. An example of a main reason in this category is the following: "Each child, regardless of their educational learning abilities, deserves the same amount of time." The final two categories; efficiency concerns in terms of maximizing human capital and/or societal welfare; and respondents' own experience as a quick or slow learner, are only ascribed to by $4 \%$ and $3 \%$, respectively. While the latter group split the resources equally on average (both quick and slow learners drew upon their own experience), the participants who state that maximizing efficiency was their main reason constitute the only group that prioritizes quick learners, on average allocating $71.4 \%$ of the resources to the quick learners. While I cannot exclude that the results are driven by a need for consistency, they map well with the finding that the priority of the slow learners may partly be driven by a preference for reducing inequalities in outcomes between the two learners.

\section{Concluding Remarks}

People's preferences for human capital investment policies are fundamental for democratic societies. At the same time, these preferences remain largely unknown and understudied. The present article reports from the first experiment on people's preferences for how society should distribute educational resources. The experiment includes a general population sample of over 2,000 Americans, where each individual allocates 12 hours of one-to-one tutoring between a quick and a slow learner, recruited via US NGOs. To study mechanisms, I handle beliefs in three ways: $i$ ) I keep important background characteristics identical between the two students, $i$ ) I exogenously vary information about the motivation of the learners and the cost efficiency of assigning tutoring to the slow learner, and iii) I elicit beliefs about the two learners and about efficiency arguments which can influence the allocation decisions.

I find that people give priority to slow learners, assigning them two thirds of the educational resources, on average. The quick learners are consequently assigned one third of the educational resources, which is a smaller, but nontrivial share. While I causally identify that cost efficiency and the motivation of 
the learners matter for the trade-off of resources between the two students, the priority of the slow learners remains robust across treatments. On average, the participants believe that the quick learners are more motivated in school, and more likely to improve their school performance with tutoring compared to the slow learners. The participants also believe that the welfare losses to society associated with the two types of students being equally distant from their full learning potential are relatively similar in size. In sum, I do not find evidence to support that the priority of slow learners is primarily driven by concerns for cost efficiency, for maximizing school performance, or for minimizing the costs to society associated with the learners not reaching their full learning potentials. However, I do find that the large majority of the participants believe slow learners will suffer at least as great individual welfare losses as the quick learners from not reaching their full learning potentials. Moreover, I find that participants who hold this belief prioritize slow learners to a greater extent when distributing educational resources. The findings provide important insights into the present policy debate about the optimal design of human capital investments by shedding light on how people think society should prioritize educational resources between different types of learners.

To learn more about whether the allocation of educational resources in the experiment is predictive of attitudes to public policies, I asked the participants about the extent to which they agreed with the following statement: "The US government should have a particular focus on helping low-performing children in school." In line with prioritizing slow learners in the allocations, the majority of the participants agreed with this statement (73.3\%). Moreover, I find that participants who assigned more tutoring to slow learners were more likely to support a particular focus on helping low-performing children in the US ($0.122, p<0.001$, Table A.5. The results are consistent with the allocation decisions in the experiment capturing underlying preferences towards relevant public policies in the US.

The present paper introduces a new experimental approach, combining the infrastructures of NGOs and data-collection agencies to let general population samples distribute actual educational resources between real students. The approach opens up many avenues of research related to preferences for human capital investment policies. Examples are studies identifying how these preferences differ between societies, and how they might change across different 
education levels. Identifying how people's preferences change in mixed-sex settings, where either a male is lagging behind or a female is lagging behind, can provide further insight on the boy crisis. Controlled variation of socioeconomic backgrounds can shed light on how people's preferences depend on the students' backgrounds. This new experimental approach also opens avenues for future research in other policy domains, such as the identification of people's preferences for health, elderly care and equal rights policies. Knowledge of people's preferences for how to distribute resources in society is fundamental for democracies, crucial in itself, and vital for assisting decision-making processes, as well as the implementation of influential policies that affect society. 


\section{References}

Ahrens, A., C.B. Hansen, and M.E. Schaffer (2018). "pdslasso and ivlasso: Programs for post-selection and post-regularization OLS or IV estimation and inference," http://ideas.repec.org/c/boc/bocode/s458459.html.

Almås, Ingvild, Alexander W. Cappelen, Kjell G. Salvanes, Erik Ø. Sørensen, and Bertil Tungodden (2016). "What explains the gender gap in college track dropout? Experimental and administrative evidence," American Economic Review: Papers \& Proceedings, 106(5): 296-302.

Almås, Ingvild, Alexander W. Cappelen, and Bertil Tungodden (2020). "Cutthroat capitalism versus cuddly socialism: Are Americans more meritocratic and efficiency-seeking than Scandinavians?" Journal of Political Economy, 128(5): 1753-1788.

Andreoni, James, Deniz Aydin, Blake Barton, B Douglas Bernheim, and Jeffrey Naecker (2020). "When fair isn't fair: Understanding choice reversals involving social preferences," Journal of Political Economy, 128(5): 1673-1711.

Attanasio, Orazio, Teodora Boneva, and Christopher Rauh (Forthcoming). "Parental beliefs about returns to different types of investments in school children," Journal of Human Resources.

Autor, David H. (2014). "Skills, education, and the rise of earnings inequality among the "other 99 percent"," Science, 344(6186): 843-851.

Autor, David H. and Melanie Wasserman (2013). "Wayward sons: The emerging gender gap in labor markets and education," Technical report, Third Way.

Barro, Robert J. (2001). "Human capital and growth," American Economic Review, 91(2): 12-17.

Becker, Gary S. (1962). "Investment in human capital: A theoretical analysis," Journal of Political Economy, 70(5): 9-49.

Berry, James, Rebecca Dizon-Ross, and Maulik Jagnani (2020). "Not playing favorites: An experiment on parental fairness preferences," NBER Working Paper No. 26732.

Black, Sandra E., Paul J. Devereux, and Kjell G. Salvanes (2005). "The more the merrier? The effect of family composition on children's outcomes," Quarterly Journal of Economics, 120(2): 669-700.

Bolton, Gary E. and Axel Ockenfels (2000). "ERC: A theory of equity, reciprocity, and competition," American Economic Review, 90(1): 166-193. 
Boneva, Teodora and Christopher Rauh (2017). "Socio-economic gaps in university enrollment: The role of perceived pecuniary and non-pecuniary returns," HCEO Working Paper 2017-080.

Boneva, Teodora and Christopher Rauh (2018). "Parental beliefs about returns to educational investments - the later the better?" Journal of the European Economic Association, 16(6): 1669-1711.

Bortolotti, Stefania, Ivan Soraperra, Matthias Sutter, and Claudia Zoller (2017). "Too lucky to be true. Fairness views under the shadow of cheating," CESifo Working Paper Series No. 6563.

Bursztyn, Leonardo (2016). "Poverty and the political economy of public education spending: Evidence from Brazil," Journal of the European Economic Association, 14(5): 1101-1128.

Busemeyer, R. Marius, Philipp Lergetporer, and Ludger Woessmann (2018). "Public opinion and the political economy of educational reforms: A survey," European Journal of Political Economy, 53(C): 161-185.

Cappelen, Alexander, Ranveig Falch, Zhongjing Huang, and Bertil Tungodden (2019a). "How do adults handle distributive conflicts among children? Experimental evidence from China and Norway," Mimeo, Norwegian School of Economics.

Cappelen, Alexander W., Astri Drange Hole, Erik Ø. Sørensen, and Bertil Tungodden (2007). "The pluralism of fairness ideals: An experimental approach," American Economic Review, 97(3): 818-827.

Cappelen, Alexander W., Ranveig Falch, and Bertil Tungodden (2019b). "The boy crisis: Experimental evidence on the acceptance of males falling behind," NHH Department of Economics Discussion Paper 06/2019.

Cappelen, Alexander W., Ranveig Falch, and Bertil Tungodden (2020). Handbook of Labor, Human Resources and Population Economics, chapter Fair and Unfair Income Inequality, Springer, Cham., pp. 1-25.

Cappelen, Alexander W., James Konow, Erik Ø. Sørensen, and Bertil Tungodden (2013). "Just luck: An experimental study of risk taking and fairness," American Economic Review, 103(3): 1398-1413.

Cappelen, Alexander W., Erik Ø. Sørensen, and Bertil Tungodden (2010). "Responsibility for what? Fairness and individual responsibility," European Economic Review, 54(3): 429-441.

Charness, Gary and Matthew Rabin (2002). "Understanding social preferences 
with simple tests," Quarterly Journal of Economics, 117(3): 817-869.

Davison, A.C. and D. V. Hinkley (1997). Bootstrap methods and their application, Cambridge University Press.

Dizon-Ross, Rebecca (2019). "Parents' beliefs about their children's academic ability: Implications for educational investments," American Economic Review, 109(8): 2728-2765.

Elango, Sneha, Jorge Luis García, James J. Heckman, and Andres Hojman (2015). "Early childhood education," Working paper 21766, National Bureau of Economic Research.

Fehr, Ernst and Klaus M. Schmidt (1999). "A theory of fairness, competition and cooperation," Quarterly Journal of Economics, 114(3): 817-868.

Finn, Chester E. Jr. and Brandon L. Wright (2015). "The bright students left behind," Wall Street Journal.

Galor, Oded and Omer Moav (2004). "From physical to human capital accumulation: Inequality and the process of development," Review of Economic Studies, 71(4): 1001-1026.

Goldin, Claudia (2016). Handbook of Cliometrics, chapter Human capital, Springer, Berlin, Heidelberg, pp. 55-86.

Goldin, Claudia and Lawrence F. Katz (2008). The Race between Education and Technology, Cambridge, Massachusetts and London, England: The Belknap Press of Harvard University Press.

Goldstein, Dana (2018). "Educators turn to programs for top students to narrow the 'excellence gap'," The New York Times.

Heckman, James (2006). "Skill formation and the economics of investing in disadvantaged children," Science, 312: 1900-1902.

Heckman, James J (2013). Giving Kids a Fair Chance, Cambridge: MIT Press.

Jensen, Robert (2010). "The (perceived) returns to education and the demand for schooling," Quarterly Journal of Economics, 125(2): 515-548.

Konow, James (2000). "Fair shares: Accountability and cognitive dissonance in allocation decisions," American Economic Review, 90(4): 1072-1091.

Konow, James (2003). "Which is the fairest one of all? A positive analysis of justice theories," Journal of Economic Literature, 41(4): 1188-1239.

Lafortune, Julien, Jesse Rothstein, and Diane Whitmore Schanzenbach (2018). "School finance reform and the distribution of student achievement," American Economic Journal: Applied Economics, 10(2): 1-26. 
Lergetporer, Philipp, Guido Schwerdt, Katharina Werner, Martin R. West, and Ludger Woessmann (2018). "How information affects support for education spending: Evidence from survey experiments in Germany and the United States," Journal of Public Economics, 167: 138-157.

Lergetporer, Philipp, Katharina Werner, and Ludger Woessmann (2020). "Educational inequality and public policy preferences: Evidence from representative survey experiments," Journal of Public Economics, 188(104226).

Manuelli, Rodolfo E. and Ananth Seshadri (2014). "Human capital and the wealth of nations," American Economic Review, 104(9): 2736-2762.

Marks, Gary N. (2014). Education, Social Background and Cognitive Ability. The decline of the social, Routledge.

Mincer, Jacob (1958). "Investment in human capital and personal income distribution," Journal of Political Economy, 66(4): 281-302.

OECD (2017). "Education at a glance 2017: OECD indicators," Technical report, OECD Publishing, Paris.

OECD (2018). "Education policy outlook 2018. Putting student learning at the centre," Technical report, OECD Publishing, Paris.

Oreopoulos, Philip and Kjell G. Salvanes (2011). "Priceless: The nonpecuniary benefits of schooling," Journal of Economic Perspectives, 25(1): 159-84.

Rodriguez-Lara, Ismael and Luis Moreno-Garrido (2012). "Self-interest and fairness: Self-serving choices of justice principles," Experimental Economics, 15(1): 158-175.

Romano, Joseph P. and Michael Wolf (2016). "Efficient computation of adjusted $p$-values for resampling-based stepdown multiple testing," Statistics \& Probability Letters, 113(1): 38-40.

Schultz, Theodore W. (1961). "Investment in human capital," American Economic Review, 51(1): 1-17. 
Figure 1: Share to quick learner

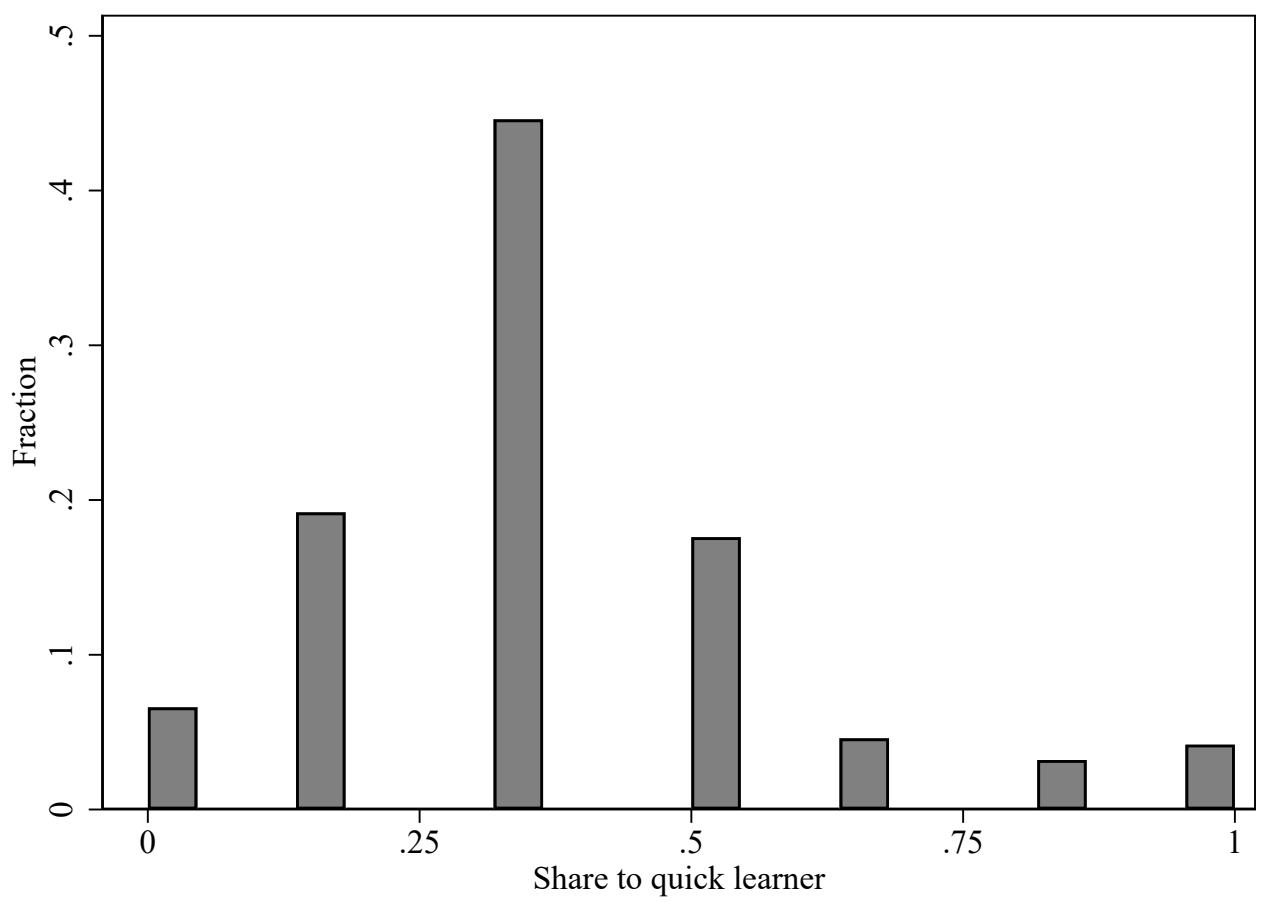

Note: The figure gives an overview of the share of tutoring assigned to the quick learner by the respondents in the base treatment (by fraction). 
Figure 2: Beliefs

(a) Relative societal welfare loss

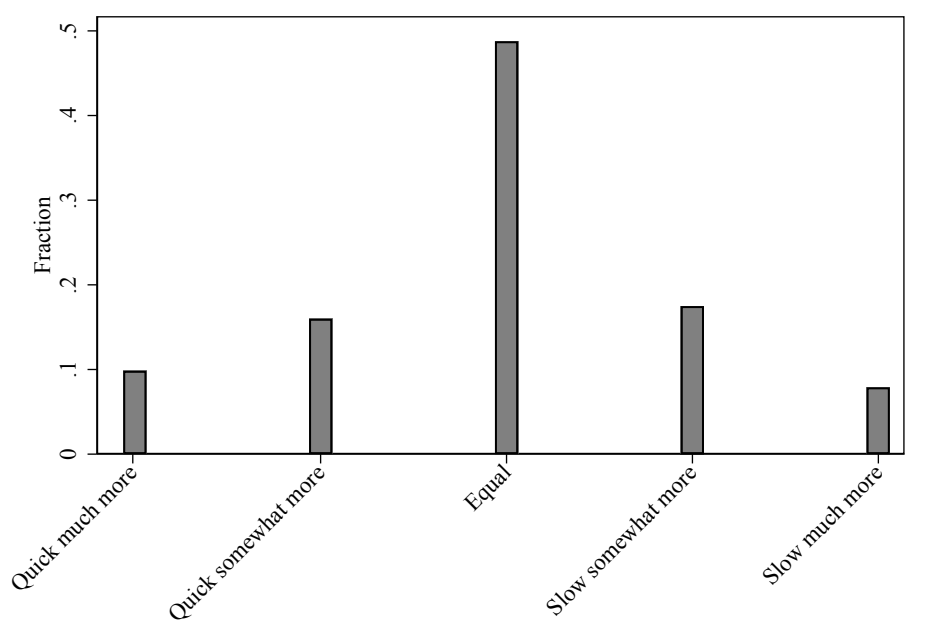

(b) Relative individual welfare loss

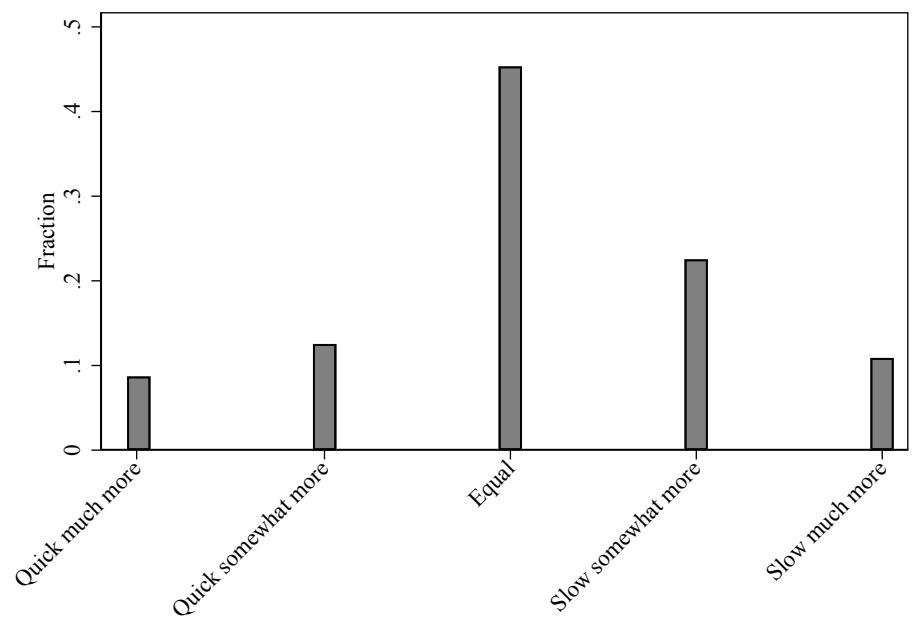

Note: The figure gives an overview of the elicited beliefs related to welfare considerations for the full sample (by fraction). Panel (a): The participants were asked about the relative welfare loss to society associated with two hypothetical students, a quick and a slow learner, being equally distant from their full learning potential. They answered on a scale from 1-5 from "Much more welfare loss to society when the quick learner does not reach it" to "Much more welfare loss to society when the slow learner does not reach it." Panel (b): The participants were asked an equivalent question with respect to individual welfare loss, and were given the equivalent scale of potential answers. 
Figure 3: Share to quick learner, by main reason

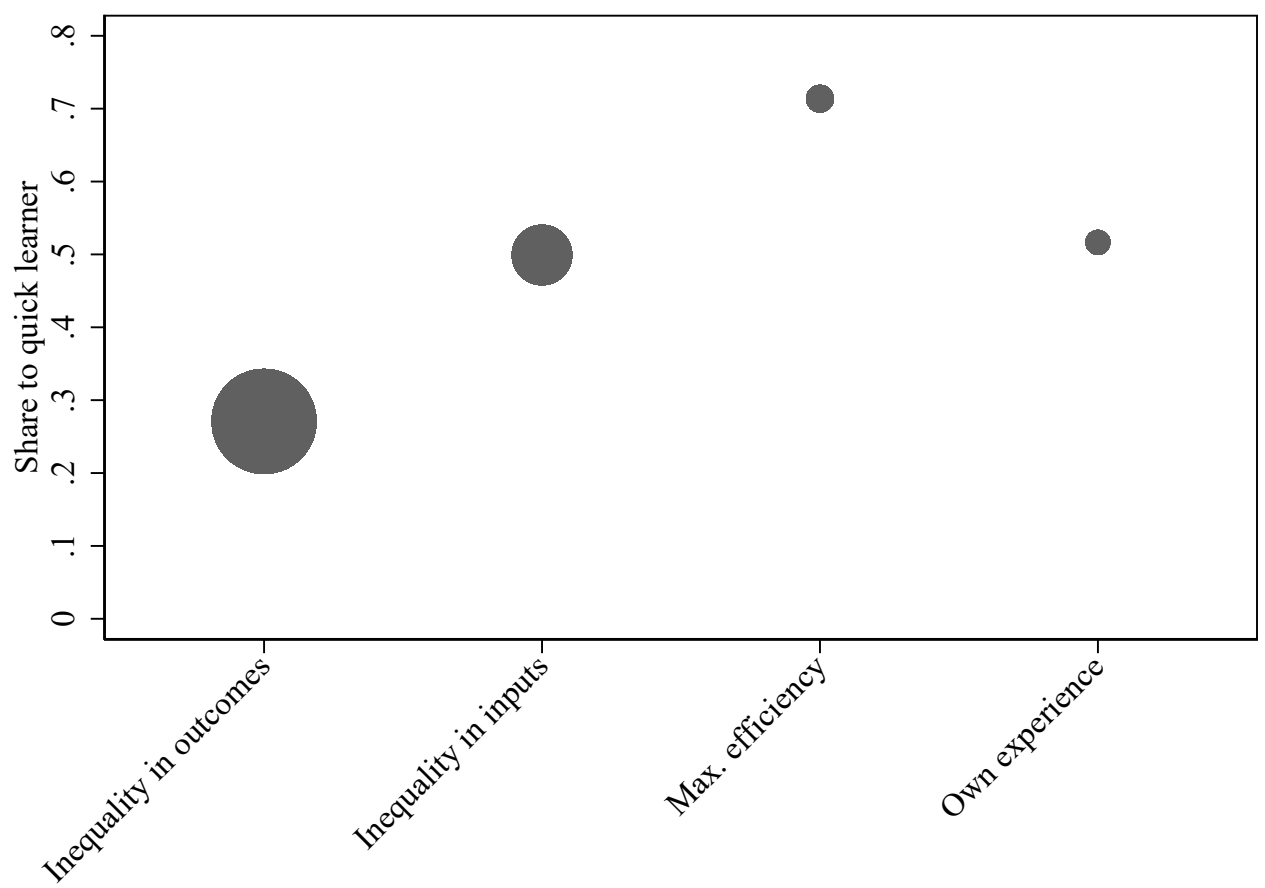

Note: The figure shows the mean share assigned to the quick learner by main reason (by fraction). The sample are participants who have provided a single main reason for the resource allocation, which fit one of the pre-determined categories (a total of 1622 participants). The categories are from left to right: i) Reducing inequality in outcomes, ii) Reducing inequality in inputs, iii) Efficiency concerns in terms of maximizing human capital and societal welfare, and iv) Own experience as slow or quick learner. Details on the categorization procedures are provided in Appendix A.5.2. 
Table 1: Descriptive statistics

\begin{tabular}{lll}
\hline & Main sample & US \\
\hline Male (share) & 0.491 & 0.492 \\
Age (year) & & \\
$\quad$ Median & 45 & 46 \\
p10 & 23 & \\
p90 & 69 & \\
Region (share) & & \\
$\quad$ Northeast & 0.174 & 0.173 \\
$\quad$ Midwest & 0.210 & 0.209 \\
$\quad$ West & 0.237 & 0.238 \\
$\quad$ South & 0.379 & 0.340 \\
Education (share) & & \\
$\quad$ High school or less & 0.334 & 0.407 \\
$\quad$ Some college or more & 0.666 & 0.593 \\
Income (USD) & & \\
$\quad$ Median & 45000 & 57500 \\
$\quad$ p10 & 29999 & 12500 \\
$\quad$ p90 & 125000 & 167500 \\
Republican (share) & 0.376 & 0.270 \\
Have children (share) & 0.640 & \\
Neighborhood characteristics: & & \\
Share non-white (median) & 0.282 & 0.266 \\
Mean 3rd grade math score (median) & 3.197 & 3.22 \\
\hline
\end{tabular}

Note: The table displays descriptive statistics for the main sample in the left column, and for the US in the right column. The descriptive statistics for the main sample are based on self-reported and ZIP-code-based data. The income variable is the yearly household income in USD (gross income before taxes are deducted) and given in standard categories where I use the mid-point in the category. A participant is classified as Republican if he or she would have voted for the Republican party. The full instructions, including a listing of income categories and definition of neighborhood characteristics, are provided in Appendix A.3.2. The share of males in the US, and the population data by region (+18) is 2017 data from the US Census Bureau, Population Division, and so is the median age (+18) (https://www.census.gov/quickfacts/fact/table/US/PST045217 and https://www.census.gov/data/datasets/2017/demo/popest/nation-detail.html, respectively). US income and education data are based on the US Census Bureau, Current Population Survey, together with the 2016 and 2017 Annual Social and Economic Supplement. The question concerning having children or not is asked differently than the question on the same topic in the US household survey. US neighborhood characteristics are taken from the Opportunity Atlas ("Neighborhood Characteristics by Census Tract"). 
Table 2: Treatments

\begin{tabular}{|l|l|l|}
\hline & Base & Efficiency \\
\hline Base & T1: $n=500$ & T2: $n=493$ \\
\hline Motivation & T3: $n=507$ & T4: $n=501$ \\
\hline
\end{tabular}


Table 3: Treatment effects, interactions

\begin{tabular}{|c|c|c|c|c|c|c|}
\hline & \multicolumn{6}{|c|}{ Share to quick learner } \\
\hline & & & & $\geq 0.5$ & $\geq 0.5$ & $\geq 0.5$ \\
\hline Efficiency & $\begin{array}{c}0.058^{* * *} \\
(0.015)\end{array}$ & $\begin{array}{c}0.060^{* * *} \\
(0.015)\end{array}$ & $\begin{array}{c}0.060^{* * *} \\
(0.015)\end{array}$ & $\begin{array}{c}0.128^{* * *} \\
(0.030)\end{array}$ & $\begin{array}{c}0.136^{* * *} \\
(0.029)\end{array}$ & $\begin{array}{c}0.135^{* * *} \\
(0.029)\end{array}$ \\
\hline Motivation & $\begin{array}{l}0.026^{*} \\
(0.014)\end{array}$ & $\begin{array}{l}0.023^{*} \\
(0.014)\end{array}$ & $\begin{array}{c}0.023 \\
(0.014)\end{array}$ & $\begin{array}{l}0.055^{*} \\
(0.029)\end{array}$ & $\begin{array}{l}0.051^{*} \\
(0.029)\end{array}$ & $\begin{array}{l}0.050^{*} \\
(0.029)\end{array}$ \\
\hline $\begin{array}{l}\text { Efficiency* } \\
\text { Motivation }\end{array}$ & $\begin{array}{l}-0.031 \\
(0.022)\end{array}$ & $\begin{array}{l}-0.035 \\
(0.021)\end{array}$ & $\begin{array}{l}-0.034 \\
(0.021)\end{array}$ & $\begin{array}{c}0.002 \\
(0.043)\end{array}$ & $\begin{array}{l}-0.010 \\
(0.042)\end{array}$ & $\begin{array}{l}-0.009 \\
(0.042)\end{array}$ \\
\hline Female & & $\begin{array}{c}-0.051 * * * \\
(0.012)\end{array}$ & $\begin{array}{c}-0.049^{* * *} \\
(0.012)\end{array}$ & & $\begin{array}{c}-0.056{ }^{* *} \\
(0.023)\end{array}$ & $\begin{array}{c}-0.052^{* *} \\
(0.023)\end{array}$ \\
\hline Republican & & $\begin{array}{c}0.016 \\
(0.011)\end{array}$ & $\begin{array}{l}0.019^{*} \\
(0.011)\end{array}$ & & $\begin{array}{c}0.012 \\
(0.022)\end{array}$ & $\begin{array}{c}0.017 \\
(0.022)\end{array}$ \\
\hline Low age & & $\begin{array}{c}0.107^{* * *} \\
(0.012)\end{array}$ & $\begin{array}{l}0.103^{* * *} \\
(0.012)\end{array}$ & & $\begin{array}{c}0.173^{* * *} \\
(0.022)\end{array}$ & $\begin{array}{c}0.167^{* * *} \\
(0.022)\end{array}$ \\
\hline Child & & $\begin{array}{l}-0.019 \\
(0.012)\end{array}$ & $\begin{array}{l}-0.015 \\
(0.012)\end{array}$ & & $\begin{array}{l}-0.045^{*} \\
(0.023)\end{array}$ & $\begin{array}{l}-0.040^{*} \\
(0.023)\end{array}$ \\
\hline Low income & & $\begin{array}{c}-0.019 \\
(0.013)\end{array}$ & $\begin{array}{c}-0.019 \\
(0.013)\end{array}$ & & $\begin{array}{l}-0.025 \\
(0.025)\end{array}$ & $\begin{array}{l}-0.025 \\
(0.025)\end{array}$ \\
\hline Low education & & $\begin{array}{c}0.033^{* * *} \\
(0.012)\end{array}$ & $\begin{array}{c}0.033^{* * *} \\
(0.012)\end{array}$ & & $\begin{array}{c}0.111^{* * *} \\
(0.024)\end{array}$ & $\begin{array}{c}0.110^{* * *} \\
(0.024)\end{array}$ \\
\hline $\begin{array}{l}\text { Non-white } \\
\text { neighborhood }\end{array}$ & & & $\begin{array}{c}0.046^{* * *} \\
(0.011)\end{array}$ & & & $\begin{array}{c}0.063^{* * *} \\
(0.023)\end{array}$ \\
\hline $\begin{array}{l}\text { Low-score } \\
\text { neighborhood }\end{array}$ & & & $\begin{array}{c}0.003 \\
(0.011)\end{array}$ & & & $\begin{array}{c}0.020 \\
(0.022)\end{array}$ \\
\hline Constant & $\begin{array}{c}0.368^{* * *} \\
(0.010)\end{array}$ & $\begin{array}{c}0.350^{* * *} \\
(0.018)\end{array}$ & $\begin{array}{c}0.320^{* * *} \\
(0.019)\end{array}$ & $\begin{array}{c}0.296^{* * *} \\
(0.020)\end{array}$ & $\begin{array}{c}0.245^{* * *} \\
(0.035)\end{array}$ & $\begin{array}{c}0.198^{* * *} \\
(0.038)\end{array}$ \\
\hline $\begin{array}{l}\text { Observations } \\
R^{2}\end{array}$ & $\begin{array}{l}2001 \\
0.009\end{array}$ & $\begin{array}{l}2001 \\
0.066\end{array}$ & $\begin{array}{l}2001 \\
0.074\end{array}$ & $\begin{array}{l}2001 \\
0.021\end{array}$ & $\begin{array}{l}2001 \\
0.067\end{array}$ & $\begin{array}{l}2001 \\
0.072\end{array}$ \\
\hline
\end{tabular}

Note: The table reports OLS regressions on the full sample, with the share assigned to the quick learner as the outcome variable in the first three columns. The outcome variable in the last three columns is an indicator variable for assigning at least half of the tutoring to the quick learner. Efficiency is an indicator for the participant being in one of the efficiency treatments, $\mathrm{T} 2$ or $\mathrm{T} 4$, with an added cost associated with assigning tutoring to the slow learner. Motivation is an indicator for the participant being in one of the motivation treatments, $\mathrm{T} 3$ and T4, receiving information of the quick learner being highly motivated. Efficiency*Motivation is the interaction of Efficiency and Motivation. Female is an indicator variable for being female. Republican is an indicator for being Republican. Low age is an indicator for being below 45 years old (the median age in the sample). Child is an indicator for the participant having at least one child. Low income is an indicator for having an income below $\$ 45,000$ (the median income in the sample). Low education is an indicator for the participant's highest educational attainment being high school or less. Non-white neighborhood is an indicator for the participant's neighborhood being less diverse than the median neighborhood (2010 Decennial Census). Low-score neighborhood is an indicator for the participant's neighborhood having a lower mean 3rd grade math test score than the median neighborhood (measured in 2013). Region indicators Northeast, Midwest, and West are also included in columns 2, 3, 5, and 6. Standard errors in parentheses, where * $\mathrm{p}$ $<0.10, * * \mathrm{p}<0.05,{ }^{* * *} \mathrm{p}<0.01$. P-values adjusted for multiple hypothesis testing are provided in Table A.6. The results are qualitatively robust to probability weighting the sample, making it representative on income and education. The results are robust to selecting control variables from the larger set of variables using machine learning (pdslasso by Ahrens, Hansen, and Schaffer (2018)). 
Table 4: Heterogeneity, background characteristics

\begin{tabular}{lcccccc}
\hline A. Efficiency & \multicolumn{5}{c}{ Share to quick learner } \\
\cline { 2 - 7 } & Gender & Politics & Age & Child & SES & All \\
\hline Efficiency & $0.076^{* * *}$ & $0.073^{* * *}$ & $0.039^{* *}$ & $0.060^{* *}$ & $0.043^{* * *}$ & 0.044 \\
& $(0.022)$ & $(0.020)$ & $(0.019)$ & $(0.028)$ & $(0.016)$ & $(0.036)$ \\
Efficiency*Female & -0.032 & & & & & -0.050 \\
& $(0.030)$ & & & & & $(0.032)$ \\
Efficiency*Republican & & -0.033 & & & & -0.030 \\
& & $(0.030)$ & & & & $0.031)$ \\
Efficiency*Low age & & & 0.045 & & & 0.053 \\
& & & $(0.031)$ & & & $0.032)$ \\
Efficiency*Child & & & & -0.000 & & 0.017 \\
& & & & $(0.033)$ & & $(0.034)$ \\
Efficiency*Low SES & & & & & $0.068^{*}$ & $0.067^{*}$ \\
& & & & & $(0.039)$ & $(0.039)$ \\
Constant & $0.363^{* * *}$ & $0.365^{* * *}$ & $0.381^{* * *}$ & $0.371^{* * *}$ & $0.380^{* * *}$ & $0.378^{* * *}$ \\
& $(0.024)$ & $(0.024)$ & $(0.023)$ & $(0.024)$ & $(0.023)$ & $(0.026)$ \\
\hline Included controls: & Yes & Yes & Yes & Yes & Yes & Yes \\
\hline Linear combination & $0.044^{* *}$ & $0.039^{*}$ & $0.084^{* * *}$ & $0.060^{* * *}$ & $0.111^{* * *}$ & \\
(Efficiency + Interaction $)$ & $(0.020)$ & $(0.023)$ & $(0.024)$ & $(0.018)$ & $(0.036)$ & \\
\hline Observations & 993 & 993 & 993 & 993 & 993 & 993 \\
$R^{2}$ & 0.076 & 0.076 & 0.077 & 0.075 & 0.078 & 0.084 \\
\hline & & & & & & \\
\hline
\end{tabular}




\begin{tabular}{|c|c|c|c|c|c|c|}
\hline \multirow[t]{2}{*}{ B. Motivation } & \multicolumn{6}{|c|}{ Share to quick learner } \\
\hline & Gender & Politics & Age & Child & SES & All \\
\hline Motivation & $\begin{array}{c}0.016 \\
(0.020)\end{array}$ & $\begin{array}{c}0.022 \\
(0.018)\end{array}$ & $\begin{array}{c}0.014 \\
(0.017)\end{array}$ & $\begin{array}{c}0.014 \\
(0.025)\end{array}$ & $\begin{array}{c}0.019 \\
(0.015)\end{array}$ & $\begin{array}{l}-0.009 \\
(0.030)\end{array}$ \\
\hline Motivation*Female & $\begin{array}{c}0.015 \\
(0.028)\end{array}$ & & & & & $\begin{array}{c}0.008 \\
(0.031)\end{array}$ \\
\hline Motivation*Republican & & $\begin{array}{c}0.005 \\
(0.028)\end{array}$ & & & & $\begin{array}{c}0.009 \\
(0.029)\end{array}$ \\
\hline Motivation*Low age & & & $\begin{array}{c}0.020 \\
(0.028)\end{array}$ & & & $\begin{array}{c}0.021 \\
(0.031)\end{array}$ \\
\hline Motivation*Child & & & & $\begin{array}{c}0.015 \\
(0.030)\end{array}$ & & $\begin{array}{c}0.017 \\
(0.031)\end{array}$ \\
\hline Motivation*Low SES & & & & & $\begin{array}{c}0.017 \\
(0.035)\end{array}$ & $\begin{array}{c}0.018 \\
(0.036)\end{array}$ \\
\hline Constant & $\begin{array}{c}0.362^{* * *} \\
(0.023)\end{array}$ & $\begin{array}{c}0.359^{* * *} \\
(0.022)\end{array}$ & $\begin{array}{c}0.363^{* * *} \\
(0.021)\end{array}$ & $\begin{array}{c}0.363^{* * *} \\
(0.024)\end{array}$ & $\begin{array}{c}0.360^{* * *} \\
(0.021)\end{array}$ & $\begin{array}{c}0.375^{* * *} \\
(0.026)\end{array}$ \\
\hline Included controls: & Yes & Yes & Yes & Yes & Yes & Yes \\
\hline $\begin{array}{l}\text { Linear combination } \\
\text { (Motivation + Interaction) }\end{array}$ & $\begin{array}{c}0.031 \\
(0.020)\end{array}$ & $\begin{array}{c}0.027 \\
(0.021)\end{array}$ & $\begin{array}{c}0.034 \\
(0.023)\end{array}$ & $\begin{array}{l}0.029^{*} \\
(0.017)\end{array}$ & $\begin{array}{c}0.036 \\
(0.032)\end{array}$ & \\
\hline $\begin{array}{l}\text { Observations } \\
R^{2}\end{array}$ & $\begin{array}{l}1007 \\
0.052\end{array}$ & $\begin{array}{c}1007 \\
0.051\end{array}$ & $\begin{array}{c}1007 \\
0.052\end{array}$ & $\begin{array}{c}1007 \\
0.052\end{array}$ & $\begin{array}{l}1007 \\
0.052\end{array}$ & $\begin{array}{c}1007 \\
0.053\end{array}$ \\
\hline
\end{tabular}

Note: The table reports OLS regressions using the sample of spectators in T1 (Base) and T2 (Efficiency) in Panel A, and T1 (Base) and T3 (Motivation) in Panel B. The outcome variable is the share assigned to the quick learner. Efficiency, Motivation, Female, Republican, Low age, Child, Low SES and region controls are indicators defined in Table 3 and Table A.1. Efficiency*Female, Efficiency*Republican, Efficiency*Low age, Efficiency*Child, and Efficiency*Low SES are interactions between the respective characteristic and Efficiency. Motivation*Female, Motivation*Republican, Motivation*Low age, Motivation*Child, and Motivation*Low SES are interactions between the respective characteristic and Motivation. Standard errors in parentheses, where * $\mathrm{p}<0.10$, ** $\mathrm{p}$ $<0.05, * * * \mathrm{p}<0.01$. P-values adjusted for multiple hypothesis testing are provided in Tables A.7 - A.10. The results are largely robust to probability weighting the sample, making it representative on income and education. 
Table 5: Correlations, beliefs

\begin{tabular}{lcccccc}
\hline & \multicolumn{5}{c}{ Share to quick learner } \\
\cline { 2 - 7 } & Base & All & Base & All & Base & All \\
\hline Quick more or equal & $0.066^{* * *}$ & $0.062^{* * *}$ & & & $0.070^{* * *}$ & $0.066^{* * *}$ \\
individual loss & $(0.020)$ & $(0.011)$ & & & $(0.022)$ & $(0.012)$ \\
Quick more or equal & & & 0.027 & $0.020^{*}$ & -0.009 & -0.009 \\
societal loss & & & $(0.022)$ & $(0.012)$ & $(0.024)$ & $(0.013)$ \\
Constant & $0.308^{* * *}$ & $0.340^{* * *}$ & $0.335^{* * *}$ & $0.367^{* * *}$ & $0.312^{* * *}$ & $0.345^{* * *}$ \\
& $(0.032)$ & $(0.018)$ & $(0.034)$ & $(0.019)$ & $(0.034)$ & $(0.019)$ \\
\hline Included controls & Yes & Yes & Yes & Yes & Yes & Yes \\
\hline Observations & 500 & 2001 & 500 & 2001 & 500 & 2001 \\
$R^{2}$ & 0.082 & 0.071 & 0.064 & 0.058 & 0.082 & 0.071 \\
\hline
\end{tabular}

Note: The table reports OLS regressions using the sample of participants in the base treatment (columns 1, 3, and 5) and the full sample (columns 2, 4, and 6). The outcome variable is the share assigned to the quick learner. Quick more or equal to individual loss is an indicator for believing that the quick learner has more or as much individual welfare loss compared to the slow learner when they are both equally distant from having achieved their full learning potential. Quick more or equal to societal loss is an indicator for believing that there is more or the same societal welfare loss associated with the quick learner compared to the slow learner being equally distant from their full learning potential. Female, Republican, Low age and Child, Low income, Low education, and region controls are included as controls and are defined in Table 3. 


\section{A Appendix}

For online publication.

\section{A.1 Figures and Tables}

Figure A.1: Share to quick learner

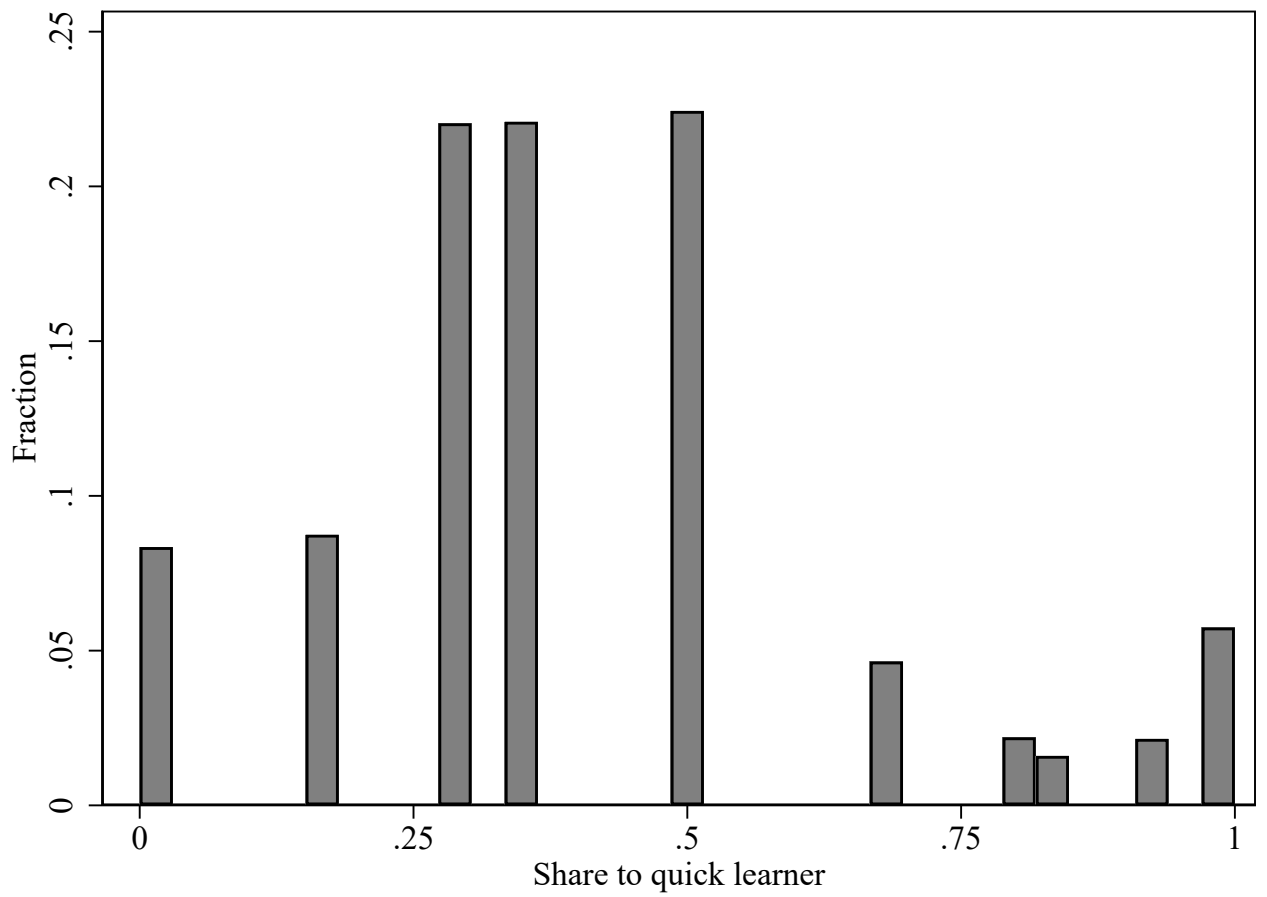

Note: The figure shows the mean share assigned to the quick learner in all of the treatments seen together (by fraction). 
Figure A.2: Share to quick learner, by treatment

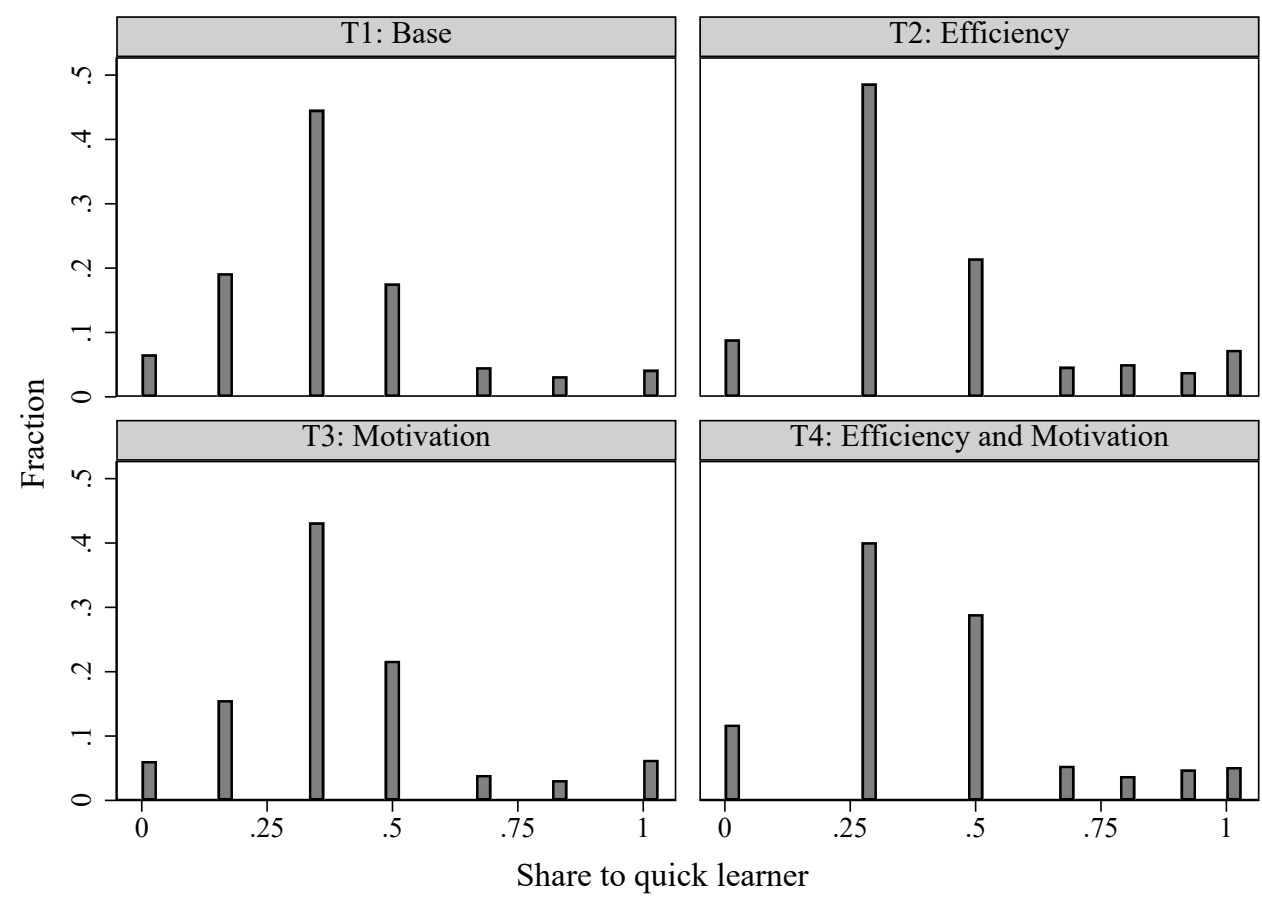

Note: The figure shows the mean share assigned to the quick learner by treatment (by fraction). 


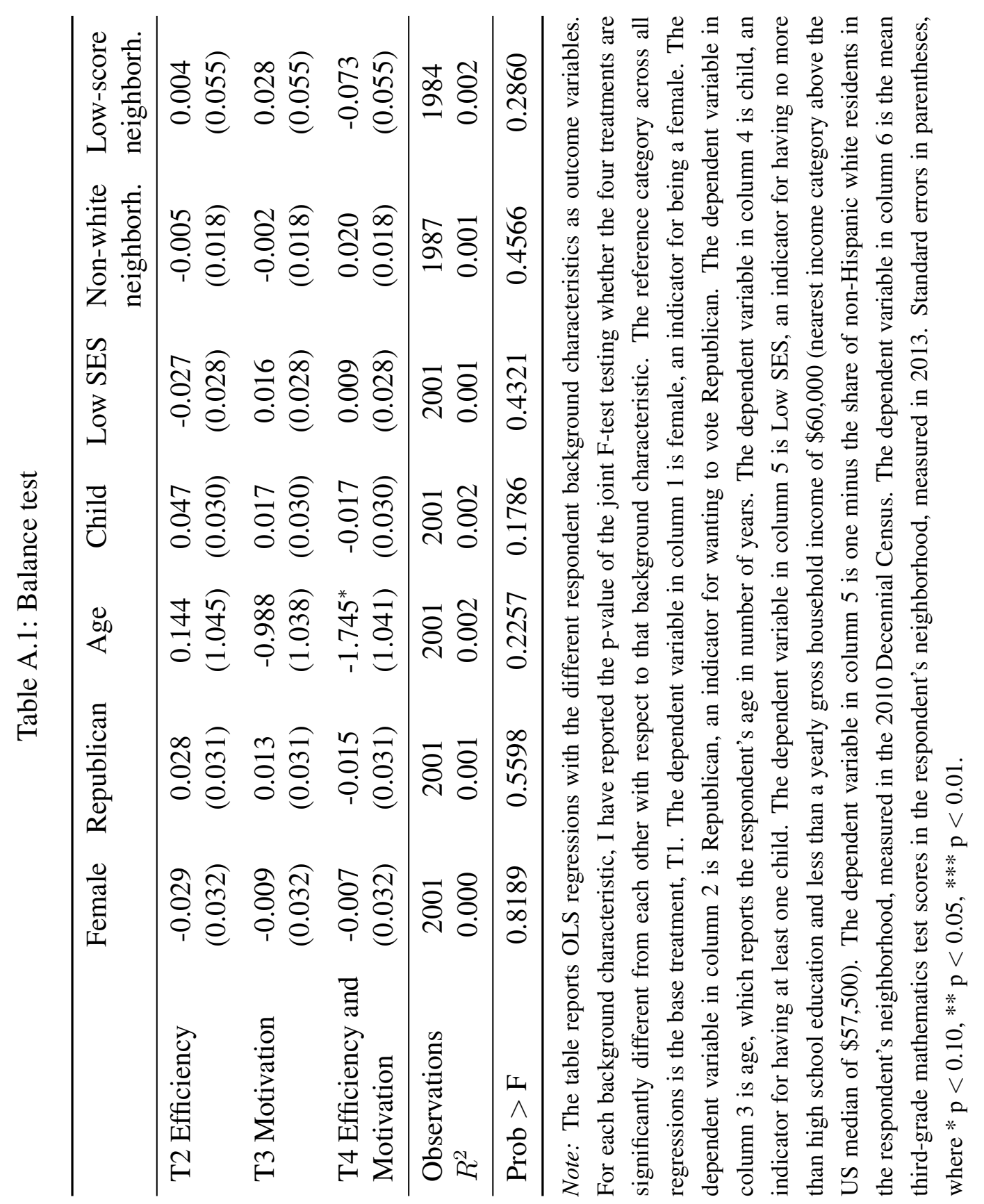


Table A.2: Beliefs about relative motivation and improvement

\begin{tabular}{|c|c|c|c|c|}
\hline & \multicolumn{4}{|c|}{ motivation (std) motivation (std) improvement (std) improvement (std) } \\
\hline Motivation & $\begin{array}{c}-0.186^{* * *} \\
(0.047)\end{array}$ & $\begin{array}{c}-0.180^{* * *} \\
(0.046)\end{array}$ & $\begin{array}{c}0.036 \\
(0.045)\end{array}$ & $\begin{array}{c}0.031 \\
(0.045)\end{array}$ \\
\hline Female & & $\begin{array}{c}0.242^{* * *} \\
(0.050)\end{array}$ & & $\begin{array}{c}0.229^{* * *} \\
(0.048)\end{array}$ \\
\hline Republican & & $\begin{array}{l}-0.059 \\
(0.050)\end{array}$ & & $\begin{array}{c}0.033 \\
(0.048)\end{array}$ \\
\hline Low age & & $\begin{array}{c}-0.201^{* * *} \\
(0.049)\end{array}$ & & $\begin{array}{l}-0.055 \\
(0.047)\end{array}$ \\
\hline Child & & $\begin{array}{l}-0.070 \\
(0.051)\end{array}$ & & $\begin{array}{c}-0.110^{* *} \\
(0.048)\end{array}$ \\
\hline Low income & & $\begin{array}{c}0.017 \\
(0.059)\end{array}$ & & $\begin{array}{l}-0.005 \\
(0.055)\end{array}$ \\
\hline Low education & & $\begin{array}{c}0.040 \\
(0.054)\end{array}$ & & $\begin{array}{c}0.140^{* * *} \\
(0.050)\end{array}$ \\
\hline Constant & $\begin{array}{l}-0.011 \\
(0.033)\end{array}$ & $\begin{array}{l}-0.010 \\
(0.071)\end{array}$ & $\begin{array}{c}0.046 \\
(0.032)\end{array}$ & $\begin{array}{c}-0.014 \\
(0.070)\end{array}$ \\
\hline $\begin{array}{l}\text { Observations } \\
R^{2}\end{array}$ & $\begin{array}{l}2001 \\
0.008\end{array}$ & $\begin{array}{c}2001 \\
0.028\end{array}$ & $\begin{array}{l}2001 \\
0.000\end{array}$ & $\begin{array}{l}2001 \\
0.018\end{array}$ \\
\hline
\end{tabular}

Note: The table reports robust OLS regressions with beliefs about relative motivation levels of the quick and the slow learner as the outcome variable in columns 1 and 2, and beliefs about relative improvement in columns 3 and 4. I use the full sample. The empirical strategy for measuring the treatment effect on beliefs is provided in Appendix A.5.1 Motivation is an indicator for the participants belonging to either of the motivation treatments, T3 Motivation or T4 Efficiency and Motivation. Beliefs about the relative motivation levels between the two students are elicited in Question 2 on a scale from 1-5, where 1 is "The quick learner is much more motivated", 2 is "The quick learner is somewhat more motivated", 3 is "They are equally motivated", 4 is "The slow learner is somewhat more motivated", and 5 is "The slow learner is much more motivated." Beliefs about the students' relative improvement with the same amount of tutoring are elicited in Question 3 on a scale from 1-5, where 1 is "The quick learner would improve much more", 2 is "The quick learner would improve somewhat more", 3 is "They would improve equally much", 4 is "The slow learner would improve somewhat more", and 5 is "The slow learner would improve much more." I consider them continuous and standardize these variables by, for each variable, subtracting the base group mean and dividing by the base group standard deviation for each observation. Female, Republican, Low age and Child, Low income, Low education, and region controls are indicators defined in Table 3 Standard errors in parentheses, where $* \mathrm{p}<0.10$, ** $\mathrm{p}<$ 0.05 , *** $\mathrm{p}<0.01$. The results are largely robust to instead using indicator variables for having an answer above or below the median on questions 2 and 3 . 
Table A.3: Heterogeneity, background characteristics

\begin{tabular}{|c|c|c|c|c|c|c|c|c|}
\hline \multirow[t]{2}{*}{ A. Efficiency } & \multicolumn{6}{|c|}{ Share to quick learner } & \multirow[b]{2}{*}{ Score } & \multirow[b]{2}{*}{ All } \\
\hline & Gender & Politics & Age & Child & SES & Diversity & & \\
\hline Efficiency & $\begin{array}{c}0.075^{* * *} \\
(0.022)\end{array}$ & $\begin{array}{c}0.070^{* * *} \\
(0.020)\end{array}$ & $\begin{array}{l}0.036^{*} \\
(0.018)\end{array}$ & $\begin{array}{l}0.057^{* *} \\
(0.028)\end{array}$ & $\begin{array}{l}0.041^{* *} \\
(0.016)\end{array}$ & $\begin{array}{c}0.048^{* * *} \\
(0.018)\end{array}$ & $\begin{array}{l}0.043^{* *} \\
(0.019)\end{array}$ & $\begin{array}{c}0.021 \\
(0.041)\end{array}$ \\
\hline Efficiency*Female & $\begin{array}{l}-0.032 \\
(0.030)\end{array}$ & & & & & & & $\begin{array}{l}-0.050 \\
(0.032)\end{array}$ \\
\hline Efficiency*Republican & & $\begin{array}{l}-0.030 \\
(0.030)\end{array}$ & & & & & & $\begin{array}{l}-0.024 \\
(0.030)\end{array}$ \\
\hline Efficiency*Low age & & & $\begin{array}{c}0.049 \\
(0.030)\end{array}$ & & & & & $\begin{array}{l}0.056^{*} \\
(0.032)\end{array}$ \\
\hline Efficiency*Child & & & & $\begin{array}{c}0.002 \\
(0.033)\end{array}$ & & & & $\begin{array}{c}0.022 \\
(0.034)\end{array}$ \\
\hline Efficiency*Low SES & & & & & $\begin{array}{c}0.071^{*} \\
(0.039)\end{array}$ & & & $\begin{array}{l}0.070^{*} \\
(0.039)\end{array}$ \\
\hline Efficiency*Non-white & & & & & & $\begin{array}{c}0.021 \\
(0.030)\end{array}$ & & $\begin{array}{c}0.010 \\
(0.031)\end{array}$ \\
\hline Efficiency*Low-score & & & & & & & $\begin{array}{c}0.031 \\
(0.030)\end{array}$ & $\begin{array}{c}0.020 \\
(0.030)\end{array}$ \\
\hline Constant & $\begin{array}{c}0.317^{* * *} \\
(0.026)\end{array}$ & $\begin{array}{c}0.320^{* * *} \\
(0.026)\end{array}$ & $\begin{array}{c}0.335^{* * *} \\
(0.026)\end{array}$ & $\begin{array}{c}0.326^{* * *} \\
(0.027)\end{array}$ & $\begin{array}{c}0.334^{* * *} \\
(0.025)\end{array}$ & $\begin{array}{c}0.330^{* * *} \\
(0.026)\end{array}$ & $\begin{array}{c}0.332^{* * *} \\
(0.026)\end{array}$ & $\begin{array}{c}0.341^{* * *} \\
(0.031)\end{array}$ \\
\hline Included controls: & Yes & Yes & Yes & Yes & Yes & Yes & Yes & Yes \\
\hline $\begin{array}{l}\text { Linear combination } \\
(\text { Eff + Interac.) }\end{array}$ & $\begin{array}{l}0.043^{* *} \\
(0.020)\end{array}$ & $\begin{array}{l}0.040^{*} \\
(0.023)\end{array}$ & $\begin{array}{c}0.085^{* * *} \\
(0.024)\end{array}$ & $\begin{array}{c}0.059^{* * *} \\
(0.017)\end{array}$ & $\begin{array}{c}0.112^{* * *} \\
(0.035)\end{array}$ & $\begin{array}{c}0.069^{* * *} \\
(0.023)\end{array}$ & $\begin{array}{c}0.074^{* * *} \\
(0.023)\end{array}$ & \\
\hline $\begin{array}{l}\text { Observations } \\
R^{2}\end{array}$ & $\begin{array}{c}993 \\
0.095\end{array}$ & $\begin{array}{c}993 \\
0.095\end{array}$ & $\begin{array}{c}993 \\
0.096\end{array}$ & $\begin{array}{c}993 \\
0.094\end{array}$ & $\begin{array}{c}993 \\
0.098\end{array}$ & $\begin{array}{c}993 \\
0.094\end{array}$ & $\begin{array}{c}993 \\
0.095\end{array}$ & $\begin{array}{c}993 \\
0.104\end{array}$ \\
\hline
\end{tabular}




\begin{tabular}{|c|c|c|c|c|c|c|c|c|}
\hline \multirow[t]{2}{*}{ B. Motivation } & \multicolumn{6}{|c|}{ Share to quick learner } & \multirow[b]{2}{*}{ Score } & \multirow[b]{2}{*}{ All } \\
\hline & Gender & Politics & Age & Child & SES & Diversity & & \\
\hline Motivation & $\begin{array}{c}0.015 \\
(0.020)\end{array}$ & $\begin{array}{c}0.020 \\
(0.018)\end{array}$ & $\begin{array}{c}0.012 \\
(0.017)\end{array}$ & $\begin{array}{c}0.015 \\
(0.025)\end{array}$ & $\begin{array}{c}0.018 \\
(0.015)\end{array}$ & $\begin{array}{l}0.038^{* *} \\
(0.018)\end{array}$ & $\begin{array}{c}0.024 \\
(0.018)\end{array}$ & $\begin{array}{c}0.001 \\
(0.038)\end{array}$ \\
\hline Motivation*Female & $\begin{array}{c}0.017 \\
(0.028)\end{array}$ & & & & & & & $\begin{array}{c}0.007 \\
(0.031)\end{array}$ \\
\hline Motivation*Republican & & $\begin{array}{c}0.008 \\
(0.028)\end{array}$ & & & & & & $\begin{array}{c}0.012 \\
(0.029)\end{array}$ \\
\hline Motivation*Low age & & & $\begin{array}{c}0.025 \\
(0.028)\end{array}$ & & & & & $\begin{array}{c}0.027 \\
(0.030)\end{array}$ \\
\hline Motivation*Child & & & & $\begin{array}{c}0.013 \\
(0.030)\end{array}$ & & & & $\begin{array}{c}0.013 \\
(0.032)\end{array}$ \\
\hline Motivation*Low SES & & & & & $\begin{array}{c}0.020 \\
(0.035)\end{array}$ & & & $\begin{array}{c}0.021 \\
(0.035)\end{array}$ \\
\hline Motivation*Non-white & & & & & & $\begin{array}{l}-0.030 \\
(0.028)\end{array}$ & & $\begin{array}{l}-0.030 \\
(0.029)\end{array}$ \\
\hline Motivation*Low-score & & & & & & & $\begin{array}{l}-0.001 \\
(0.028)\end{array}$ & $\begin{array}{c}0.005 \\
(0.028)\end{array}$ \\
\hline Constant & $\begin{array}{c}0.332^{* * *} \\
(0.025)\end{array}$ & $\begin{array}{c}0.329^{* * *} \\
(0.024)\end{array}$ & $\begin{array}{c}0.332^{* * *} \\
(0.024)\end{array}$ & $\begin{array}{c}0.332^{* * *} \\
(0.026)\end{array}$ & $\begin{array}{c}0.330^{* * *} \\
(0.024)\end{array}$ & $\begin{array}{c}0.321^{* * *} \\
(0.024)\end{array}$ & $\begin{array}{c}0.327^{* * *} \\
(0.024)\end{array}$ & $\begin{array}{c}0.338^{* * *} \\
(0.030)\end{array}$ \\
\hline Included controls: & Yes & Yes & Yes & Yes & Yes & Yes & Yes & Yes \\
\hline $\begin{array}{l}\text { Linear combination } \\
\text { (Mot + Interac.) }\end{array}$ & $\begin{array}{c}0.032 \\
(0.019) \\
\end{array}$ & $\begin{array}{c}0.029 \\
(0.021) \\
\end{array}$ & $\begin{array}{c}0.036 \\
(0.022)\end{array}$ & $\begin{array}{l}0.028^{*} \\
(0.017)\end{array}$ & $\begin{array}{c}0.038 \\
(0.032)\end{array}$ & $\begin{array}{c}0.009 \\
(0.021)\end{array}$ & $\begin{array}{c}0.023 \\
(0.021)\end{array}$ & \\
\hline $\begin{array}{l}\text { Observations } \\
R^{2}\end{array}$ & $\begin{array}{l}1007 \\
0.062\end{array}$ & $\begin{array}{l}1007 \\
0.062\end{array}$ & $\begin{array}{l}1007 \\
0.062\end{array}$ & $\begin{array}{l}1007 \\
0.062\end{array}$ & $\begin{array}{l}1007 \\
0.062\end{array}$ & $\begin{array}{l}1007 \\
0.063\end{array}$ & $\begin{array}{r}1007 \\
0.062\end{array}$ & $\begin{array}{l}1007 \\
0.064\end{array}$ \\
\hline
\end{tabular}

Note: The table reports OLS regressions using the sample of participants in T1 (Base) and T2 (Efficiency) in Panel A, and T1 (Base) and T3 (Motivation) in Panel B. The outcome variable is the share assigned to the quick learner. Efficiency, Motivation, Female, Republican, Low age, Child, Low SES, Non-white, Low-score, and region controls are indicators defined in Table 3 and Table A.1 Efficiency*Female, Efficiency*Republican, Efficiency*Low age, Efficiency*Child, Efficiency*Low SES, Efficiency*Non-white, and Efficiency*Low-score are interactions between the respective characteristic and Efficiency. Motivation*Female, Motivation*Republican, Motivation*Low age, Motivation*Child, Motivation*Low SES, Motivation*Non-white, and Motivation*Low-score are interactions between the respective characteristic and Motivation. Standard errors in parentheses, where $* \mathrm{p}<0.10, * * \mathrm{p}<0.05, * * * \mathrm{p}<$ 0.01. P-values adjusted for multiple hypothesis testing are provided in Tables A.7 A.10 
Table A.4: Heterogeneity combined treatment, background characteristics

\begin{tabular}{|c|c|c|c|c|c|c|}
\hline & \multicolumn{6}{|c|}{ Share to quick learner } \\
\hline & Gender & Politics & Age & Child & SES & All \\
\hline EffMot & $\begin{array}{l}0.051^{* *} \\
(0.021)\end{array}$ & $\begin{array}{l}0.039^{* *} \\
(0.019)\end{array}$ & $\begin{array}{c}0.031 \\
(0.019)\end{array}$ & $\begin{array}{c}0.020 \\
(0.025)\end{array}$ & $\begin{array}{c}0.058^{* * *} \\
(0.017)\end{array}$ & $\begin{array}{c}0.004 \\
(0.035)\end{array}$ \\
\hline EffMot*Female & $\begin{array}{l}-0.004 \\
(0.030)\end{array}$ & & & & & $\begin{array}{l}-0.020 \\
(0.032)\end{array}$ \\
\hline EffMot*Republican & & $\begin{array}{c}0.025 \\
(0.030)\end{array}$ & & & & $\begin{array}{c}0.022 \\
(0.031)\end{array}$ \\
\hline EffMot*Low age & & & $\begin{array}{c}0.036 \\
(0.030)\end{array}$ & & & $\begin{array}{c}0.049 \\
(0.033)\end{array}$ \\
\hline EffMot*Child & & & & $\begin{array}{c}0.045 \\
(0.031)\end{array}$ & & $\begin{array}{c}0.051 \\
(0.032)\end{array}$ \\
\hline EffMot*Low SES & & & & & $\begin{array}{l}-0.037 \\
(0.037)\end{array}$ & $\begin{array}{l}-0.034 \\
(0.037)\end{array}$ \\
\hline Constant & $\begin{array}{c}0.342^{* * *} \\
(0.024)\end{array}$ & $\begin{array}{c}0.348^{* * *} \\
(0.024)\end{array}$ & $\begin{array}{c}0.353^{* * *} \\
(0.023)\end{array}$ & $\begin{array}{c}0.357^{* * *} \\
(0.025)\end{array}$ & $\begin{array}{c}0.338^{* * *} \\
(0.024)\end{array}$ & $\begin{array}{c}0.365^{* * *} \\
(0.026)\end{array}$ \\
\hline Included controls: & Yes & Yes & Yes & Yes & Yes & Yes \\
\hline $\begin{array}{l}\text { Linear combination } \\
\text { (EffMot + Interaction) }\end{array}$ & $\begin{array}{l}0.046^{* *} \\
(0.021)\end{array}$ & $\begin{array}{c}0.064^{* * *} \\
(0.024)\end{array}$ & $\begin{array}{c}0.067^{* * *} \\
(0.023)\end{array}$ & $\begin{array}{c}0.065^{* * *} \\
(0.018)\end{array}$ & $\begin{array}{c}0.021 \\
(0.033)\end{array}$ & \\
\hline Observations & 1001 & 1001 & 1001 & 1001 & 1001 & 1001 \\
\hline$R^{2}$ & 0.062 & 0.062 & 0.063 & 0.064 & 0.063 & 0.068 \\
\hline
\end{tabular}

Note: The table reports OLS regressions using the sample of participants in T1 (Base) and T4 (Efficiency and Motivation). The outcome variable is the share assigned to the quick learner. EffMot, Female, Republican, Low age, Child, Low SES, and region controls are indicators defined in Table 3 and Table A.1 EffMot*Female, EffMot*Republican, EffMot*Low age, Eff$M o t^{*}$ Child, and EffMot $*$ Low SES are interactions between the respective characteristic and EffMot. Standard errors in parentheses, where * $\mathrm{p}<0.10, * * \mathrm{p}<0.05, * * * \mathrm{p}<0.01$. 
Table A.5: External validity results

\begin{tabular}{lcc}
\hline & \multicolumn{2}{c}{ Share to quick learner } \\
\cline { 2 - 3 } & Base & All \\
\hline Support for & $-0.103^{* * *}$ & $-0.122^{* * *}$ \\
low-performers & $(0.023)$ & $(0.013)$ \\
Constant & $0.423^{* * *}$ & $0.474^{* * *}$ \\
& $(0.034)$ & $(0.019)$ \\
\hline Included controls & Yes & Yes \\
\hline Observations & 500 & 2001 \\
$R^{2}$ & 0.103 & 0.104 \\
\hline
\end{tabular}

Note: The table reports OLS regressions using the sample of participants in the base treatment in column 1 and the full sample in column 2. The outcome variable is the share assigned to the quick learner. Support for low-performers is an indicator for agreeing that the US government should have a particular focus on helping low-performing children in school. Female, Republican, Low age, Child, Low income, Low education, and region controls are included as controls and are defined in Table 3 


\section{A.2 Multiple Hypothesis Testing}

I here report the p-values adjusted for multiple hypothesis testing. I calculate unadjusted p-values as bootstrap p-values following Davison and Hinkley (1997) and compute p-values adjusted for stepdown multiple testing following the algorithm proposed by Romano and Wolf (2016). Bootstrapping is done with 10,000 replications.

Table A.6: Multiple hypothesis adjustments: Average treatment effects (share to quick learner)

\begin{tabular}{llll}
\hline & Differences & $\begin{array}{l}\text { Unadjusted } \\
\text { p-values }\end{array}$ & $\begin{array}{l}\text { Romano-Wolf-adjusted } \\
\text { p-values }\end{array}$ \\
\hline Treatment effects & & & \\
Base vs. efficiency & 0.058 & 0.000 & 0.001 \\
Base vs. motivation & 0.026 & 0.068 & 0.115 \\
Base vs. efficiency*motivation & -0.031 & 0.154 & 0.154 \\
\hline
\end{tabular}

Note: The multiple hypothesis adjustment is based on OLS regression specification (1) without control variables. Column 1 reports the estimated treatment effects (the difference in the share assigned to the quick learner). Column 2 reports the unadjusted p-values and column 3 reports the Romano-Wolf-adjusted p-values. 
Table A.7: Multiple hypothesis adjustments: Treatment effect (share to quick learner) T1 vs. T2

\begin{tabular}{llll}
\hline & Differences & $\begin{array}{l}\text { Unadjusted } \\
\text { p-values }\end{array}$ & $\begin{array}{l}\text { Romano-Wolf-adjusted } \\
\text { p-values }\end{array}$ \\
\hline Male & 0.076 & 0.001 & 0.006 \\
Female & 0.044 & 0.028 & 0.103 \\
Non-Republican & 0.073 & 0.000 & 0.003 \\
Republican & 0.039 & 0.083 & 0.103 \\
High age & 0.039 & 0.038 & 0.103 \\
Low age & 0.084 & 0.000 & 0.005 \\
No child & 0.060 & 0.034 & 0.103 \\
Child(ren) & 0.060 & 0.001 & 0.006 \\
High SES & 0.043 & 0.007 & 0.036 \\
Low SES & 0.111 & 0.001 & 0.012 \\
\hline
\end{tabular}

Note: The multiple hypothesis adjustment is based on OLS regression specification (2), one for each dimension: gender, political preference, age, having children and SES. The dependent variable is share assigned to the quick learner. The sample is the individuals in T1 (Base) and T2 (Efficiency). Background characteristic indicators are defined in Table 3 and Table A.1 along with the included region controls. Column 1 reports the estimated treatment effects (the difference in the share assigned to the quick learner in T1 (Base) and T2 (Efficiency)). Column 2 reports the unadjusted p-values and column 3 reports the Romano-Wolf-adjusted p-values. 
Table A.8: Multiple hypothesis adjustments: Subgroup differences in treatment effect (share to quick learner) T1 vs. T2

\begin{tabular}{llll}
\hline & Differences & $\begin{array}{l}\text { Unadjusted } \\
\text { p-values }\end{array}$ & $\begin{array}{l}\text { Romano-Wolf-adjusted } \\
\text { p-values }\end{array}$ \\
\hline Females vs. males & -0.032 & 0.300 & 0.603 \\
Republicans vs. non-Republicans & -0.033 & 0.270 & 0.603 \\
Low age vs. high age & 0.045 & 0.145 & 0.445 \\
Child(ren) vs. no child & -0.000 & 0.997 & 0.997 \\
Low SES vs. high SES & 0.068 & 0.084 & 0.359 \\
\hline
\end{tabular}

Note: The multiple hypothesis adjustment is based on OLS regression specification (2), one for each dimension: gender, political preference, age, having children and SES. The dependent variable is share assigned to the quick learner. The sample is the individuals in T1 (Base) and T2 (Efficiency). Background characteristic indicators are defined in Table 3 and Table A.1 along with the included region controls. Column 1 reports the estimated subgroup differences in treatment effect (the difference in the share assigned to the quick learner in T1 (Base) and T2 (Efficiency)). Column 2 reports the unadjusted p-values and column 3 reports the Romano-Wolf-adjusted p-values. 
Table A.9: Multiple hypothesis adjustments: Treatment effect (share to quick learner) T1 vs. T3

\begin{tabular}{llll}
\hline & Differences & $\begin{array}{l}\text { Unadjusted } \\
\text { p-values }\end{array}$ & $\begin{array}{l}\text { Romano-Wolf-adjusted } \\
\text { p-values }\end{array}$ \\
\hline Male & 0.016 & 0.411 & 0.744 \\
Female & 0.031 & 0.116 & 0.508 \\
Non-Republican & 0.022 & 0.231 & 0.674 \\
Republican & 0.027 & 0.202 & 0.674 \\
High age & 0.014 & 0.400 & 0.744 \\
Low age & 0.034 & 0.135 & 0.522 \\
No child & 0.014 & 0.562 & 0.744 \\
Child(ren) & 0.029 & 0.077 & 0.411 \\
High SES & 0.019 & 0.198 & 0.674 \\
Low SES & 0.036 & 0.261 & 0.674 \\
\hline
\end{tabular}

Note: The multiple hypothesis adjustment is based on OLS regression specification [2], one for each dimension: gender, political preference, age, having children, and SES. The dependent variable is share assigned to the quick learner. The sample is the individuals in T1 (Base) and T3 (Motivation). Background characteristic indicators are defined in Table 3 and Table A.1 along with the included region controls. Column 1 reports the estimated treatment effects (the difference in the share assigned to the quick learner in T1 (Base) and T3 (Motivation)). Column 2 reports the unadjusted p-values and column 3 reports the Romano-Wolf-adjusted p-values. 
Table A.10: Multiple hypothesis adjustments: Subgroup differences in treatment effect (share to quick learner) T1 vs. T3

\begin{tabular}{llll}
\hline & Differences & $\begin{array}{l}\text { Unadjusted } \\
\text { p-values }\end{array}$ & $\begin{array}{l}\text { Romano-Wolf-adjusted } \\
\text { p-values }\end{array}$ \\
\hline Females vs. males & 0.015 & 0.599 & 0.975 \\
Republicans vs. non-Republicans & 0.005 & 0.865 & 0.975 \\
Low age vs. high age & 0.020 & 0.482 & 0.975 \\
Child(ren) vs. no child & 0.015 & 0.611 & 0.975 \\
Low SES vs. high SES & 0.017 & 0.639 & 0.975 \\
\hline
\end{tabular}

Note: The multiple hypothesis adjustment is based on OLS regression specification (2), one for each dimension: gender, political preference, age, having children, and SES. The dependent variable is share assigned to the quick learner. The sample is the individuals in T1 (Base) and T3 (Motivation). Background characteristic indicators are defined in Table 3 and Table A.1 along with the included region controls. Column 1 reports the estimated subgroup differences in treatment effect (the difference in the share assigned to the quick learner in T1 (Base) and T3 (Motivation)). Column 2 reports the unadjusted p-values and column 3 reports the Romano-Wolf-adjusted p-values. 


\section{A.3 Instructions}

\section{A.3.1 Consent Form}

Introduction

Welcome to this research project. We appreciate your participation. This study is a project conducted by FAIR/The Choice Lab at NHH Norwegian School of Economics. The project is funded by several research institutions. Participants are recruited via Research Now with the aim of surveying a representative sample of Americans.

Study

The study takes about 5 minutes. It consists of distributing educational resources and of answering a set of questions on your beliefs and attitudes. You will also be asked to answer a set of background questions. Please note that you will be asked to provide your zip code as part of the study. This will only be used to identify neighborhood demographics and will be deleted prior to data analysis, such that the data is anonymous.

\section{Confidentiality}

All data obtained from you will be treated confidentially and the data will only be reported in an aggregate format (by reporting only combined results and never reporting individual ones). The project is scheduled for completion by April 2019. All submissions will be concealed, and no one other than the primary investigator will have access to them. The data collected via Qualtrics and will be stored on a secure server at $\mathrm{NHH}$.

\section{Voluntary participation}

It is voluntary to participate in the project, and you can at any time choose to withdraw your consent without stating any reason. If you decide to withdraw, your data will not be used and will be deleted.The study has been notified to the Data Protection Official for Research, NSD - Norwegian Centre for Research Data.

Questions about the Research 
If subjects have questions about this study or their rights, or if they wish to lodge a complaint or concern, they may contact us at the following email: thechoicelab@nhh.no

I have received information about the project and am willing to participate. Yes/No

\section{A.3.2 Background Questions}

\section{Demograhics}

- What is your sex?

- Male

- Female

- How old are you?

$-16 / 17 / \ldots / 99$

- In which state do you currently reside?

- Alabama/Alaska/...list of all states in the US/I do not reside in the US.

- What is the highest level of education you have completed?

- Less than High School

- High School/GED

- Some College

- Associate's Degree

- Bachelor's Degree

- Master's Degree

- Professional Degree (JD, MD)

- Doctoral Degree 
- What is your household's combined yearly income (gross income before taxes are deducted)?

- Less than $\$ 29,999$

- $\$ 30,000-\$ 59,999$

- $\$ 60,000$ - $\$ 99,999$

- \$100,000 - \$149,999

- $\$ 150,000$ or more

- Which political party would you vote for if there was an election tomorrow?

- Republican

- Democratic

- Other

- Do you have children?

- Yes/No

- What is the zip code of your current residence?

\section{Linking ZIP-codes to background characteristics}

I convert the reported ZIP-codes to corresponding census tracts, and match the census tracts with neighborhood characteristics for each participant in the main data collection, using data from the Opportunity Atlas ("Neighborhood Characteristics by Census Tract") ${ }^{17}$ The analysis is focused around two variables from the Opportunity Atlas data set. These two variables are ${ }^{18}$

- nonwhite_share2010: One minus the share of non-Hispanic white residents in the county, measured in the 2010 Decennial Census.

- gsmn_math_g3_2013: Mean third-grade mathematics test scores in 2013. Obtained from the Stanford Education Data Archive and measured at the district level. A crosswalk is created from districts to tracts by weighting by the proportion of land area that a given school district covers in a tract.

\footnotetext{
${ }^{17}$ https://opportunityinsights.org/

${ }^{18} \mathrm{https}$ ///opportunityinsights.org/wp-content/uploads/2019/07/Codebook-for-Table-9.pdf
} 


\section{A.3.3 Instructions: Distributive Choice}

\section{Treatment 1: Base}

In contrast to traditional survey questions that are about hypothetical situations, we now ask you to make a choice that may have real consequences for two children. We ask you to distribute educational resources between two middleschool students from the US. The two students are both girls from economically disadvantaged families. One of them learns quickly, the other takes more time and learns slower.

We ask you to distribute 12 hours of one-to-one tutoring between these two students. We will randomly select some of the choices from this survey to be implemented. The students will receive the resources allocated to them without any information about the survey. Your decision is completely anonymous.

Please state which of the following alternatives you choose:

- The quick learner receives 12 hours of tutoring and the slow learner receives 0 hours of tutoring.

- The quick learner receives 10 hours of tutoring and the slow learner receives 2 hours of tutoring.

- The quick learner receives 8 hours of tutoring and the slow learner receives 4 hours of tutoring.

- The quick learner receives 6 hours of tutoring and the slow learner receives 6 hours of tutoring.

- The quick learner receives 4 hours of tutoring and the slow learner receives 8 hours of tutoring.

- The quick learner receives 2 hours of tutoring and the slow learner receives 10 hours of tutoring.

- The quick learner receives 0 hours of tutoring and the slow learner receives 12 hours of tutoring.

\section{Treatment 2: Efficiency}

In contrast to traditional survey questions that are about hypothetical situations, 
we now ask you to make a choice that may have real consequences for two children. We ask you to distribute educational resources between two middleschool students from the US. The two students are both girls from economically disadvantaged families. One of them learns quickly, the other takes more time and learns slower.

We ask you to distribute 12 hours of one-to-one tutoring between these two students. We will randomly select some of the choices from this survey to be implemented. The students will receive the resources allocated to them without any information about the survey. Your decision is completely anonymous. Please note that if you choose to increase the amount of tutoring to the slow learner by 1 hour, the amount of tutoring to the quick learner is decreased by 2 hours.

Please state which of the following alternatives you choose:

- The quick learner receives 12 hours of tutoring and the slow learner receives 0 hours of tutoring.

- The quick learner receives 10 hours of tutoring and the slow learner receives 1 hours of tutoring.

- The quick learner receives 8 hours of tutoring and the slow learner receives 2 hours of tutoring.

- The quick learner receives 6 hours of tutoring and the slow learner receives 3 hours of tutoring.

- The quick learner receives 4 hours of tutoring and the slow learner receives 4 hours of tutoring.

- The quick learner receives 2 hours of tutoring and the slow learner receives 5 hours of tutoring.

- The quick learner receives 0 hours of tutoring and the slow learner receives 6 hours of tutoring.

\section{Treatment 3: Motivation}


I include the following sentence at the end of the description of the students in Treatment 1: Base.

The quick learner is a highly motivated student.

\section{Treatment 4: Efficiency and Motivation}

I include the following sentence at the end of the description of the students in Treatment 2: Efficiency.

The quick learner is a highly motivated student.

\section{A.3.4 Beliefs and Attitudes}

We will now ask you a few questions regarding the choice you just made.

1. What was the main reason for your choice? Please explain.

2. If you had to guess, how do you think the level of motivation differs between the quick and the slow learner?

- The quick learner is much more motivated.

- The quick learner is somewhat more motivated.

- They are equally motivated.

- The slow learner is somewhat more motivated.

- The slow learner is much more motivated.

3. Compared to each other, how do you think the two students would improve their school performance if they were given the same number of hours of tutoring?

- The quick learner would improve much more.

- The quick learner would improve somewhat more.

- The would improve equally much.

- The slow learner would improve somewhat more. 
- The slow learner would improve much more.

We will now ask you questions regarding a different set of individuals, for whom you did not make a distributive choice.

Please consider two individuals who who have finished their education. One of them learns quickly, the other takes more time and learns slower. Neither of them have achieved their full learning potential and both are equally far away from it.

4. Which of the individuals do you think has more welfare loss in life? Is it more welfare loss to the quick learner or the slow learner when they do not reach their full learning potentials?

- The quick learner has much more welfare loss.

- The quick learner has somewhat more welfare loss.

- They have the same amount of welfare loss.

- The slow learner has somewhat more welfare loss.

- The slow learner has much more welfare loss.

5. Please consider again two individuals who have finished their education. When do you think there is more welfare loss to society? Is it more welfare loss to society associated with the quick learner or the slow learner not reaching his/her full learning potential?

- Much more welfare loss to society when the quick learner does not reach it.

- Somewhat more welfare loss to society when the quick learner does not reach it.

- The same amount of welfare loss to society for each of them not reaching it.

- Somewhat more welfare loss to society when the slow learner does not reach it.

- Much more welfare loss to society when the slow learner does not reach it. 
6. We now want you to indicate to what extent you agree with the following statement. 1 means that you agree completely with the statement on the left, 10 means that you agree completely with the statement on the right, and the numbers in between indicate the extent to which you agree or disagree with the statements.

The US

The US

governgovern-

ment

should

ment

have a

should

particular

not have

focus on

a particu-

helping

lar focus

low-

on help-

performing

ing low-

children

performing

in school.

1

2

3

4

$5 \quad 6$

children

in school.

10

\section{A.4 Follow-up}

The consent form is equivalent to the consent form provided in A.3.1, and the background questions are identical to the background questions listed in A.3.2.

\section{A.4.1 Beliefs, Follow-up}

The participants are randomized into a treatment involving two girls, or a treatment involving two boys. The treatments are otherwise identical. The instructions involving two girls are provided below:

\section{Question 1}

We would like you to imagine two middle-school students from the US. These two middle-school students are both girls from economically disadvantaged families. One of them learns quickly, the other takes more time and learns slower.

When you think about these two students, what would you expect to be their 


\section{grade point averages (GPAs) when they leave middle-school?}

$\mathrm{F}$ (0 points) is the lowest possible GPA, while A (4 points) is the highest possible GPA.

The slow learner: $(\mathrm{F}: 0) /(\mathrm{D}: 1) /(\mathrm{C}: 2) /(\mathrm{B}: 3) /(\mathrm{A}: 4)$

The quick learner: (F:0)/(D:1)/(C:2)/(B:3)/(A:4)

\section{A.5 Empirical Specifications}

\section{A.5.1 Effect of Motivation Treatments on Beliefs}

The participants were asked about their beliefs about the two learners' relative motivation level. I use the responses from this question to test how the motivation treatments affect beliefs on relative motivation, and use the following empirical specification:

$$
\text { indmot }_{i}=\beta_{0}+\beta_{1} T 3 T 4_{i}+\boldsymbol{\beta}_{2} \mathbf{X}_{i}+\varepsilon_{i},
$$

where indmot is participant $i$ 's belief about the relative motivation level of the quick and the slow learner and $T 3 T 4_{i}$ is an indicator for participant $i$ belonging to a treatment where the participant is informed that the quick learner is highly motivated (T3 or T4).

To see whether the motivation treatments affect beliefs about relative improvement with the same amount of tutoring, I replace indmot with indimpr in (3) and regress (3) on the full sample again. The results are provided in Table A.2, columns 3 and 4 .

\section{A.5.2 Method of Categorization of Main Reason}

Just after the participants had made their distributive decision, they were asked: "What was the main reason for your choice? Please explain." The answers were coded according to pre-determined categories based on 100 random responses. Two research assistants who did not know the aim of the study coded all responses independently before merging their categorizations, discussing differences where necessary. Out of the 2001 responses, 1622 participants had an- 
swers which fit uniquely to one of the four categories: i) Reducing inequality in outcomes, ii) Reducing inequality in inputs, iii) Efficiency concerns in terms of maximizing human capital and societal welfare, and iv) Own experience as slow or quick learner. 